ANLIFPPITM-166
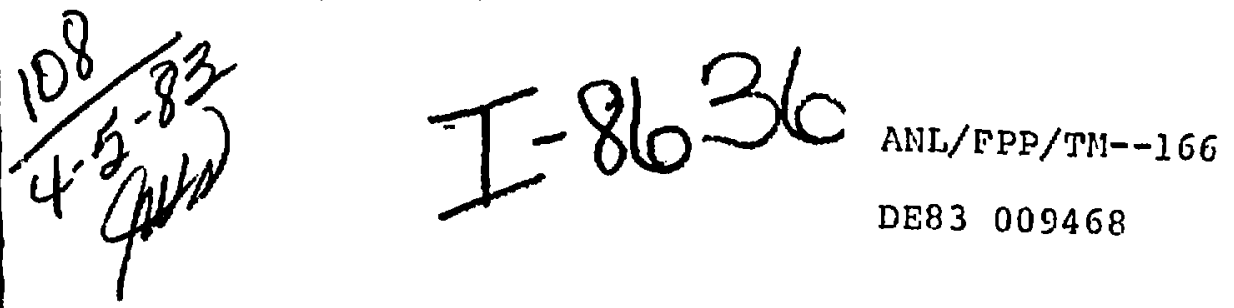

\title{
EFFECTS OF IRRADIATION ON CERAMICS FOR FUSION-REACTOR APPLICATIONS
}

\author{
by \\ D. L. Porter
}

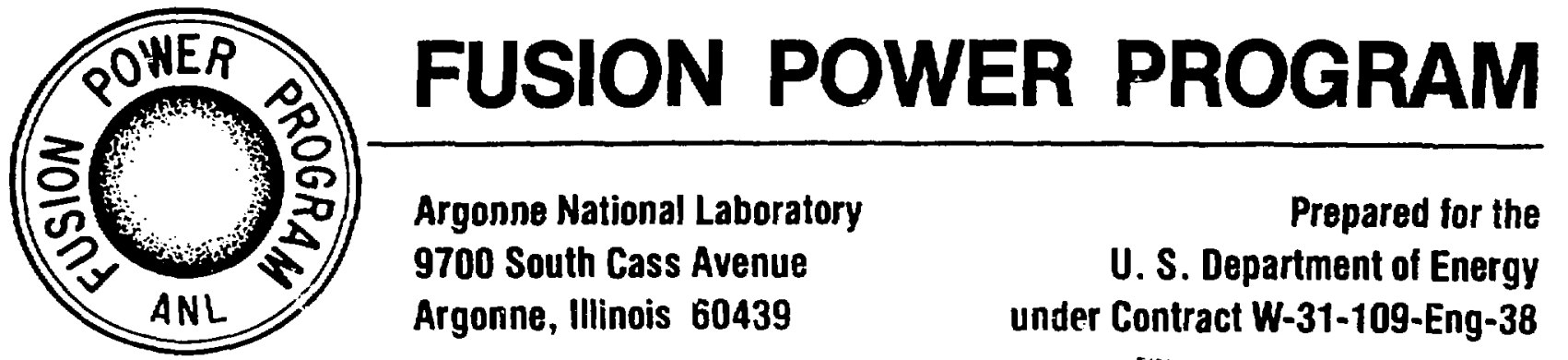


ANL/FPP/TM-166

\author{
ARGONNE NATIONAL LABORATORY \\ 9700 South Cass Avenue \\ Argonne, Illinois 60439
}

\title{
EFFECTS OF IRRADIATION ON CERAMICS \\ FOR FUSION-REACTOR APPLICATIONS
}

by

D. L. Porter

EBR-II Project

\section{DISCLAIMER}

This report was prepared as an account of work sponsored by an agency of the United States Government. Neither the United States Government nor any agency thereof, nor any of their employees, makes any warranty, express or implied, or assumes any legal liability or responsibility for the accuracy, completeness, or usefulness of any information, apparatus, product, or process disclosed, or represents that its use would not infringe privately ownod rights. Reference herein to any specific commercial product, process, or service by trade name, trademark, manufaclurer, or otherwise does not necessarily constitute or imply its endorsement, recommendation, or favoring by the United States Government or any agency thereof. The views and opinions of authors expressed herein do not necessarily state or reflect thoue of the United States Government or any agency thereof.

December 1982 


\section{TABLE OF CONTENTS}

ABSTRACT

Page

viii

I. INTRODUCTION

II. EXPERIMENTAL JUSTIFICATION AND DETAIL 1

A. Justification and Objectives 1

B. Experimental Detail 3

III. RESULTS AND DISCUSSION 9

$\mathrm{Al}_{2} \mathrm{O}_{3} \quad 9$

$\begin{array}{ll}\mathrm{MgO} & 16\end{array}$

$\mathrm{SiO}_{2} \quad 17$

HR66B + COO and MS01I-A Glass Ceramics 22

ReX Glass Ceramic 28

Corning Glass Ceramics: Macor, DH, DI, DJ 47

$\mathrm{ZrO}_{2}$

IV. CONCLUSIONS 50

ACKNOWLEDGEMENTS

REFERENCES 


\section{LIST OF FIGURES}

Figure No.

Description

Page

Axial Fast (E>70.1 MeV) Neutron Flux Profile for EBR-II

Reactor Row 7. Fusion materials were contained within +7 inches of core centerline.

Axial Temperature Profile for $X 133$ Capsules. Fusion materials were contained within \pm 7 inches of core centerline.

Axial Temperature Profile for $\times 147$ Capsules. Fusion materials were contained within \pm 7 inches of core centerline.

Transmission Electron Micrograph of a Neutron-irradiated $\left(550^{\circ} \mathrm{C}\right) \mathrm{Al}_{2} \mathrm{O}_{3}$ Single Crystal Material. Note the apparent alignment $\delta f^{3}$ small $(\sim 5 \mathrm{~nm})$ voids along the $C$-axis of the $\mathrm{Al}_{2} \mathrm{O}_{3}$. $200 \mathrm{kV}$.

Transmission Electron Micrograph of a Neutron-Irradiated $\left(550^{\circ} \mathrm{C}\right) \mathrm{Al}_{2} \mathrm{O}_{3}$ Single Crystal Material. The photo shot near [2TTO zone axis conditions, shows the small faults, or twins, which were found to exist everywhere in this material. $200 \mathrm{kV}$. $\mathrm{AT}_{2} \mathrm{O}_{3}$ (a. $400^{\circ} \mathrm{C}$, b. $550^{\circ} \mathrm{C}$ ). Note the brown coloration in ${ }^{2}{ }^{3} 1$ samples, resulting from some type of oxygenvacancy defect created during irradiation.

Scanning Electron Micrographs of the Previously Optically-flat Surfaces of As-irradiated $\mathrm{Al}_{2} \mathrm{O}_{3}$. The arrowed features may be a blistering effect? transparent material. Glass (Infracil). The photos include an entire sample (a) and a cross-section of the sample (b). Note the brown coloration appearing in the geometric center of the sample.

Infracil. Note that within experimental accuracy the expansion coefficient ( 1 inear) is the same as that observed in unirradiated material. 


\section{LIST OF FIGURES (contd)}

Figure No.

Descriptiun

Page

Thermal Expansion Data for $550^{\circ} \mathrm{C}$ Neutron-irradiated

Infracil. Note that within experimental accuracy the expansion coefficient (linear) is the same as that observed in unirradiated material.

$\gamma$-Scan Results of the Capsule Section Containing the HR66B + CoO Glass Ceramic. A neutron radiograph (left) has been included for reference. Note that ${ }^{58} \mathrm{Co}$ and ${ }^{54} \mathrm{Mn}$ show only the stainless steel capsule material, while the ${ }^{60} \mathrm{Co}$ trace shows the activation of the ceramic.

Thermal Expansion Data for Unirradiated HR66B + CoO Glass Ceramic (glassy form).

Thermal Expansion Data for Unirradiated HR66B + CoO Glass

Ceramic (ceramic form).

Thermal Expansion Data for Unirradiated MS011-A Glass

Ceramic (glassy form).

Thermal Expansion Data for Unirradiated MSO11-A Glass Ceramic (ceramic form).

Transmission Electron Micrograph of $550^{\circ} \mathrm{C}$ Neutronirradiated ReX Glass Ceramic (ceramic form). The needlelike features are the lithium silicate crystal phase. $200 \mathrm{kV}$.

Transmission Electron Micrographs of Neutron-irradiated ReX Showing Vitrification of the Lithium Silicate in the Electron Beam. Photos were taken at $\approx 45$-second intervals. Vitrification was complete (c) in less than 2 minutes. $200 \mathrm{kV}$.

Time Sequence Electron Micrographs Showing "Bubble (Void)" Formation in As-neutron-irradiated ReX (glassy form). The electron irradiation causes the void formation, a) $4 \mathrm{~m} 40 \mathrm{~s}$; b) $6 \mathrm{~m} 40 \mathrm{~s}$; c) $9 \mathrm{~m}$; d) $15 \mathrm{~m}$; e) $25 \mathrm{~m}$; f) $40 \mathrm{~m}$. $200 \mathrm{kV}$.

21 Thermal Expansion Data for Unirradiated ReX Glass Ceramic (glassy form). ReX Glass Ceramic (glassy form). 


\section{LIST OF FIGURES (contd)}

Figure №.

Description

Page

24

Thermal Expansion Data for Unirradiated ReX Glass Ceramic (ceramic form).

25 Thermal Expansion Data for $400^{\circ} \mathrm{C}$ Neutron-irradiated ReX Glass Ceramic (ceramic form).

26

Thermal Expansion Data for $550^{\circ} \mathrm{C}$ Neutron-irradiated ReX

46

Glass Ceramic (ceramic form).

27

Transmission Electron Micrographs of Unirradiated (a) and Neutron-irradiated (b) DH Glass Ceramic. Note the irradiation-induced lens-shaped defects which formed between mica plates causing weakening of the material. $200 \mathrm{kV}$. 


\section{LIST OF TABLES}

Table No.

Description

Page

1

Corning Glass Ceramics: Composition

5

2

Sandia Glass Ceramics: Composition

5

3

$\mathrm{Al}_{2} \mathrm{O}_{3}$ Volume Expansion

10

4

Mg0 Density Change

16

5

Infracil Density Change

20

6

Infracil Microhardness

22

7

Density Changes in HR66B + CoO and MSO11-A

28

8

Hardness and Fracture Toughness of ReK

33

9

ReX Density Changes

35

10

Corning Glass Ceramics Density Results

48 


\section{ABSTRACT}

The purpose of this study, coordinated with efforts of LANL and Grumman Aircraft, was to lay some basic groundwork to study the irradiation effects on the engineering properties of some useful classes of ceramic materials; ANL's efforts were pointed towards multiphase materials (glass ceramics and partially-stabilized zirconias). The materials were irradiated at $400^{\circ} \mathrm{C}$ and $550^{\circ} \mathrm{C}$ to fast (E>0.1 MeV) neutron fluences of $\sim 2 \times 10^{22} \mathrm{n} / \mathrm{cm}^{2}$. Fluorophlogapite mica based glass ceramics (Macor, etc.) were found susceptible to weakening due to void formation between mica plates. Composition variations within this class of glass ceramics seemed to cause sharp variations in the magnitude of the effect. Lithium silicate glass ceramic (ReX) showed sharp contrasts between the effects of ionization irradiation and displacement damage, neutron irradiation having little effect on the ReX structure while electron irradiation creating lithium silicate vitrification and rapid structural annealing. Pure dry silica (Infracil) and pure alumina showed discoloration at large neutron doses, the silica discoloration having a peculiar geometric effect. Thermal expansion was not greatly affected in any of the materials, while some showed minor amounts of swelling or densification. The study clearly pointed out the need for data of this kind before ceramics are selected for component use in fusion reactors. 


\section{INTRODUCTION}

The purpose of the experiment is to utilize the fast flux and hard neutron spectrum environment of EBR-II to assess certain aspects of radiation damage in materials important to fusion reactor design. The particular materials and experimental details were chosen as a result of cooperative interaction between ourselves, LANL (ceramics, Frank Clinard), and Grumman Aircraft (ceramics, Al Tobin). The purpose of this report is to first demonstrate the need for such experiments and then to review the results obtained thus far.

\section{EXPERIMENTAL JUSTIFICATION AND DETAIL}

\section{a. Justification and Objectives}

Traditionally, the study of irradiation damage in ceramic materials has been very limited and confined primarily to basic science studies. This is understandable because, with the exception of ceramic fuels, fission reactor technology has found little or no use for refractory or insulating materials. For this reason, simulation studies (electron, light ion, or heavy ion irradiation) comprise the majority of the investigations and most all studies have been concerned with simple basic ceramics, as is usually the case in basic science studies. The only obvious deviation from this scenario has been the few experiments performed by $F$. W. Clinard and his group at Los Alamos National Laboratories where initial scoping studies on the neutron irradiation effects in a variety of engineeringly important ceramics were carried out. The results of their work have been outlined recently in a single paper. ${ }^{4}$ 
In contrast, radiation effects in metallic materials of engineering importance have been widely studied for the past 10-12 years. While certain subtleties of in-reactor performance still need investigation and better performing materials are constantly being sought, the semi-quantitative predictability of performance of a wide class of metallic materials in fast neutron environments is now in hand. The fusion materials efforts are, however, extremely heavily weighted towards solving problems related to metallic material applications.

It is for these reasons that this study was coordinated to confirm and extend earlier findings on some basic ceramics and, more importantly, to extend the data base to a wide class of engineeringly important composite and multi-phase ceramic materials. LANL has included materials such as several magnesium-aluminum spinels which have shown tendencies towards unusually high radiation damage resistance, SiC and $\mathrm{Si}_{3} \mathrm{~N}_{4}$ which have excellent mechanical properties, and carbon-cirbon composites which are used in extreme thermal environments such as Space Shuttle shielding. We have filled out the material matrix with $\mathrm{Al}_{2}{ }_{3}$ and dry silica (possible window materials), some partialiy stabilized zirconias which show promise for having excellent strength and fracture toughress through alloy design, and seven types of glass ceramics. The glass ceramics may be especially important because these can be used structurally and can be compositionally modified to match the thermal expansion of metallic materials to which they may be joined. Moreover, many of these glass ceramics are machinable, a unique quality in ceramics which makes fabrication of large and intricate components considerably 
easier. Grumman Aircraft has already decided to use Macor, a Corningproduced glass ceramic, in the TFTR reactor at Princeton. Grumman has included some special tests for Macor-type ceramics in our experiment. LANL has also realized the importance of these ceramics and has, in the past year, performed some low-fluence irradiations on Macor in other lower-flux reactors. Their results have shown no volume changes at $\sim 10^{18} \mathrm{n} / \mathrm{cm}^{2}$ and little or no degradation in strength. Early predictions by some well-known experts have prophesied that the weakly bonded glass ceramics would readily decompose in an irradiation environment. It is clear that the need for increased knowledge of neutron-irradiation effects on ceramics exists and efforts should be made to fill the gap between metals and ceramics.

\section{B. Experimental Detail}

The previous section of this report contains a brief outline of the materials contained in the ceramic-related portion of this experiment. In more detail, the seven glass ceramics include four Corning products, Macor, DH, DI, and DJ, all of which come from the same general class, that being fluorophlogapites, where the crystal phase is a form of fluorinebonded mica. The Macor is the most machinable of the four. The other three glass ceramics are Sandia-modified forms of other classes of glass ceramics in which the compositions are designed so that their thermal expansion coefficients match a structural metallic material to which they can be bonded. HR66B + CoO matches the expansion of 300-series stainless steels, MSO11-A matches that of Mo, and ReX can be used with Inconel alloys. 
The Sandia-produced glass ceramics were included in both the as-melted glassy form as well as the finished semi-crystalline forn. This allows a study of the tendency for the glass to further crystallize in reactor, as weli as to separate irradiation effects on the glass and crystalline phases. The composition of the glass ceramics appear in Tables 1 and 2 .

Most of the ceramics were sealed in He-filled Type 316 stainless steel capsules with the exception of Macor, DH, DI, and DJ glass ceramics, which were individually sealed in small capsules under, a rough vacuum ( $30 \mu \mathrm{m}$ Hg pressure, $5.8 \times 10^{-4} \mathrm{psi}$ ). The reason for doing this was to test the binding stability of these ceramics; it has been suggested that weakly bonded glass ceramics may tend to break down into gas and metal-colloid products upon irradiation. Subsequent gas analysis of the capsules through laser puncturing would show this effect as well as F-outgassing and He production from the ${ }^{10} \mathrm{~B}$ in the Macor.

The short, sample-holding capsules fit into eight 39.5-in. vehicle capsules (identical to their sister creep capsules). The short capsules were supported at axial elevations extending $\sim 6 \mathrm{in}$. on either side of core centerline. These axial positions achieve maximum possible fluxes and minimum temperature gradients. Typical flux and temperature profiles are shown in Figures 1,2, and 3. Four each of the vehicle capsules were included in creep experiments $X 133\left(\sim 400^{\circ} \mathrm{C}\right)$ and $X 147\left(\sim 550^{\circ} \mathrm{C}\right)$ respectively. Each group of four contained approximately identical sets of specimens. 
Table 1 -- Corning Glass Ceramics

\begin{tabular}{lcccccccc}
\multirow{2}{*}{$\begin{array}{c}\text { Glass } \\
\text { Designation }\end{array}$} & $\mathrm{Al}_{2} \mathrm{O}_{3}$ & $\mathrm{MgO}$ & $\mathrm{As}_{2} \mathrm{O}_{5}$ & $\mathrm{~B}_{2} \mathrm{O}_{3}$ & $\mathrm{ZrO}_{2}$ & $\mathrm{~K}_{2} \mathrm{O}$ & $\mathrm{SiO}_{2}$ & $\mathrm{MgF}_{2}$ \\
Macor* & 15 & 15 & -- & 9 & -- & 9 & 52 & -- \\
DH & -- & 13.5 & 2.0 & -- & -- & 13.5 & 60.5 & 10.4 \\
DI & -- & 13.8 & -- & -- & -- & 13.8 & 61.7 & 10.6 \\
DJ & -- & 12.3 & 1.9 & -- & 1.9 & 15.1 & 58.8 & 10.1
\end{tabular}

*Fluorine is added to 6.3 wt $\%$ to substitute for oxygen.

Table 2 -- Sandia Glass Ceramics

Glass Ceramic Type

$\operatorname{ReX}$

$H R 66 B+C O O$

MS011 $\cdots A$
Wt \% Oxide

$$
\begin{aligned}
& \mathrm{SiO}_{2}-71.8 \\
& \mathrm{~B}_{2} \mathrm{O}_{3}-3.2 \\
& \mathrm{Al}_{2} \mathrm{O}_{3}-5.1 \\
& \mathrm{Li}_{2} \mathrm{O}-12.6 \\
& \mathrm{~K}_{2} \mathrm{O}-4.8 \\
& \mathrm{P}_{2} \mathrm{O}_{5}-2.5 \\
& \mathrm{SiO}_{2}-60.0 \\
& \mathrm{Li}_{2} \mathrm{O}^{\mathrm{O}}-9.0 \\
& \mathrm{BaO}_{0}-28.5 \\
& \mathrm{P}_{2} \mathrm{O}_{5}-2.0 \\
& \mathrm{CoO}-0.5
\end{aligned}
$$$$
\mathrm{SiO}_{2}-46.2
$$$$
\text { ZnO }-32.2
$$$$
\mathrm{Ai}_{2} \mathrm{O}_{3}-9.5
$$$$
\mathrm{BaO}-4.8
$$$$
\mathrm{P}_{2} \mathrm{O}_{5}-2.5
$$$$
\mathrm{Na}_{2} \mathrm{O}-4.8
$$ 


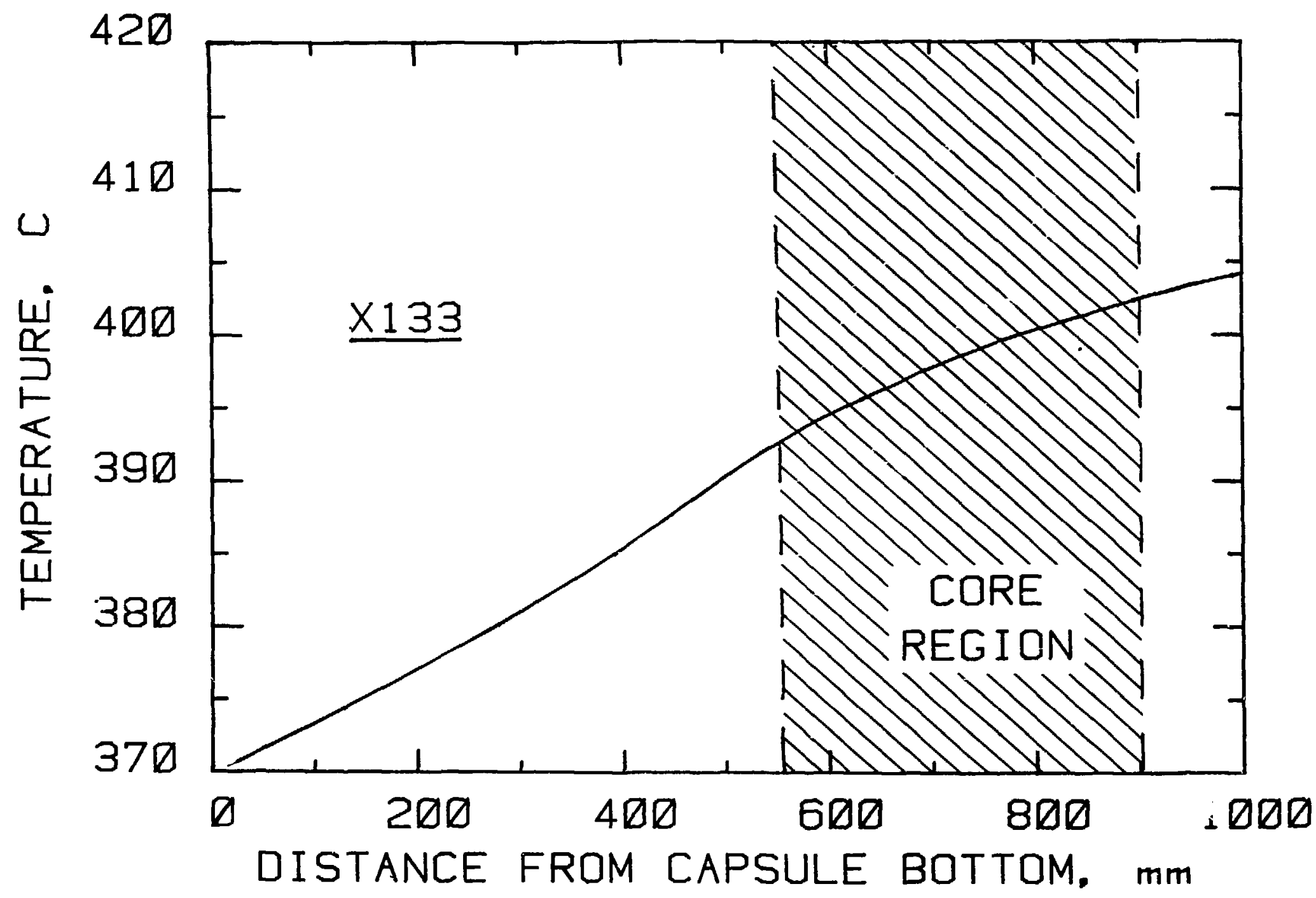

Figure 2. Axial Temperature Profile for $X 733$ Capsules. Fusion materials samples were contained within $\pm 180 \mathrm{~mm}$ of core centerline. 


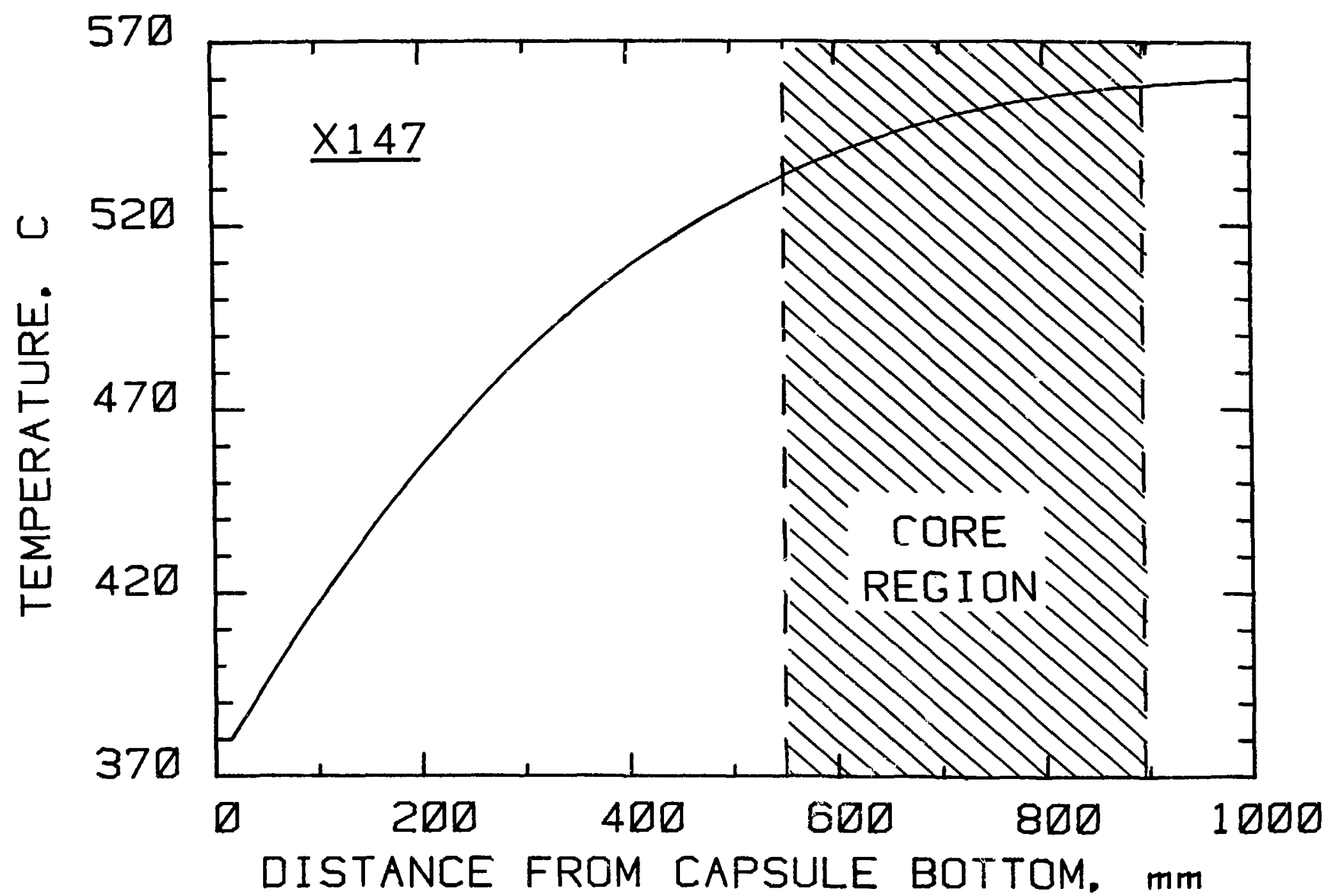

Figure 3. Axial Temperature Profile for X147 Capsules. Fusion materials samples were contained within $\pm 180 \mathrm{~mm}$ of core centerline. 
Irradiation began in March 1979 (EBR-II reactor run 100). After three reactor runs the experiments were removed for interim examination which consisted of a set of neutron radiographs of the capsules. This occurred in September 1979 after the samples had been exposed to maxiumum fast ( $E>0.1 \mathrm{MeV}$ ) neutron fluences of $\sim 1.2 \times 10^{22} \mathrm{n} / \mathrm{cm}^{2}$. The radiographs proved that all specimens had maintained structural integrity (specimens had not fragmented), so all capsules were put back into EBR-II for three additional rear:tor runs (Nos. 104-106) and were removed for capsule sectioning and destructive examinations in Aprit 1980. The following sections will concern discussion of the results of the examinations which have been performed to date. They do not reflect all the examinations which had been planned for this experiment.

\section{RESULTS AND DISCUSSION}

$$
\mathrm{Al}_{2} \mathrm{O}_{3}
$$

Examinations of the single-crystal $\mathrm{Al}_{2} \mathrm{O}_{3}$ material has thus far consisted of visual examinations, scanning electron microscopy (SEM), transmission electron microscopy (TEM), and density. The density results have shown that the $\mathrm{Al}_{2} \mathrm{O}_{3}$ swelled both at $400^{\circ} \mathrm{C}$ and at $550^{\circ} \mathrm{C}$ (see Table 3 ). Note that the volume expansion at $400^{\circ} \mathrm{C}$ exceeds that of the $550^{\circ} \mathrm{C}$-irradiated material despite having accumulated a much lower neutron fluence. These results apparently contradict a swelling vs temperature curve published recently by Hobbs ${ }^{1}$ which show a swelling peak for $\mathrm{Al}_{2} \mathrm{O}_{3}$ at $\sim 800^{\circ} \mathrm{C}$, the swelling decreasing rapidly at decreasing temperatures. Further, his curves as referenced above, which show swelling data for a number of ceramic materials, are characterized by a single swelling peak for each 
ceramic, indicating that this is a basic characteristic for this phenomenon, as many of the curves are constructed from 3-5 data points.

Table 3 -- $\mathrm{Al}_{2} \mathrm{O}_{3}$ Volume Expansion

$\begin{array}{lcc}\Delta V / V_{0}, \% & T_{i r r},{ }^{\circ} \mathrm{C} & \phi \mathrm{t}, 10^{22} \mathrm{n} / \mathrm{cm}^{2} \\ & 400 & 1.25 \\ 2.9 & 550 & 2.07\end{array}$

Our data and the previous work may not, in fact, be contradictory, but may demonstrate the existence of a low-temperature swelling peak; the previous work was done at $T_{i r r} \geq 600^{\circ} \mathrm{C}$. Double peaks in swelling vs temperature curves have been observed in a number of metallic materials and there is no reason to believe that ceramic materials are immune from such effects. If indeed there does exist a low-temperature swelling peak as the data indicates, then this extension of the data base to lower temperatures could be very significant and points out the need for more extensive data to even qualitatively predict the in-reactor behavior of these materials.

A cursory transmission electron microscopic examination of the $550^{\circ} \mathrm{C}$-irradiated $\mathrm{Al}_{2} \mathrm{O}_{3}$ has indicated that at least some of the volume expansion can be attributed to $50 \AA$ sized voids, bubbles, or colloids (currently thought to be voids, ${ }^{2}$ (see Fig. 4). These microstructural features have previously been observed in both ion-irradiated ${ }^{3}$ and 


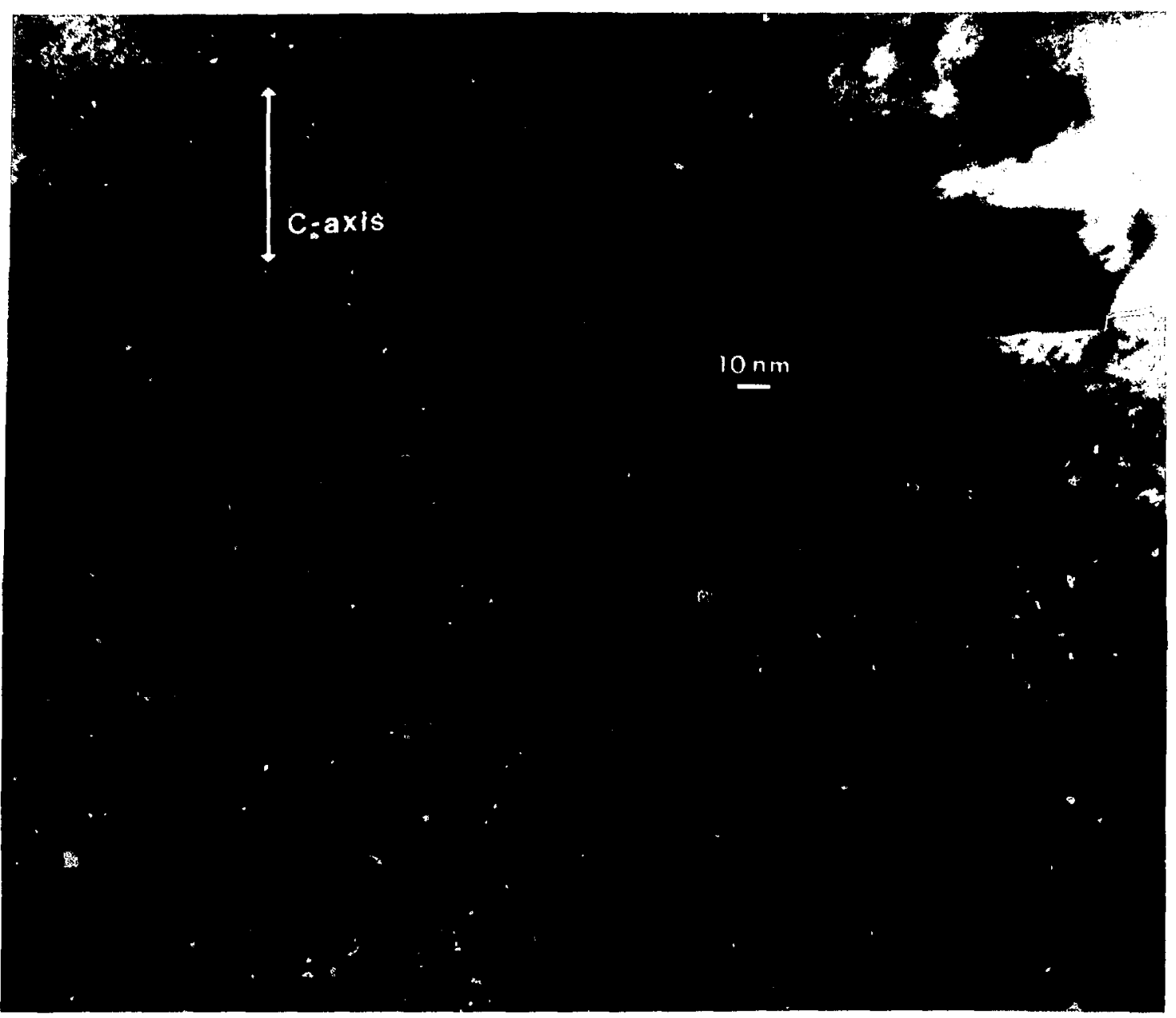

Fig. 4 Transmission Electron Micrograph of a Neutron-Irradiated $\left(550^{\circ} \mathrm{C}\right) \mathrm{Al}_{2} \mathrm{O}_{3}$ Single Crystal Material. Note the apparent alignment of small $(\sim 5 \mathrm{~nm})$ voids along the $\mathrm{C}$-axis of the $\mathrm{Al}_{2} \mathrm{O}_{3}$. $200 \mathrm{kV}$. 
neutron-irradiated ${ }^{4} \mathrm{Al}_{2} \mathrm{O}_{3}$. The previously noted $\mathrm{C}$-axis alignment of the voids can also be seen in Fig. 4. In addition to the voids, a very fine scale faulting or twinning was sbserved (see Fig. 5); I do not believe that this effect has been previously reported. More detailed TEM examinations are necessary to precisely describe the nature and probable cause of this faulting phenomenon.

Figure $6(a, b)$ shows the visual appearance of the irradiated $\mathrm{Al}_{2} \mathrm{O}_{3}$. The material was originaliy clear and after neutron irradiation shows a distinct yellow or brown coloration. While this effect has apparently not commoniy been reported, Primak ${ }^{5}$ has observed it, but states that it may be impurity dependent, as has been associated with luminescence effects seen after $x$-irradiation. While the purity of this material was not reported, our $\mathrm{Al}_{2} \mathrm{O}_{3}$ had only $200 \mathrm{ppm}$ levels of impurities, mostly Fe and $\mathrm{Nb}$. Moreover, we know that $\mathrm{Al}_{2} \mathrm{O}_{3}$ can appear yellow, or brown, through doping it with $\mathrm{Mg}^{2+}$. The effect is to create color centers in the form of oxygen vacancies. It therefore seems very reasonable that neutron irradiation of even ultra pure $\mathrm{Al}_{2} \mathrm{O}_{3}$ may produce such oxygen vacancies and therefore the deleterious absorption bands which make $\mathrm{Al}_{2} \mathrm{O}_{3}$ appear brown.

The SEM examinations of the optically flat $\mathrm{Al}_{2} \mathrm{O}_{3}$ surfaces showed very little, but certain features as shown in Fig. 7, resembled blister caps, perhaps formed by implantation of the capsule He. Examination of surfaces of unirradiated material is needed to confirm whether these features are irradiation induced. 


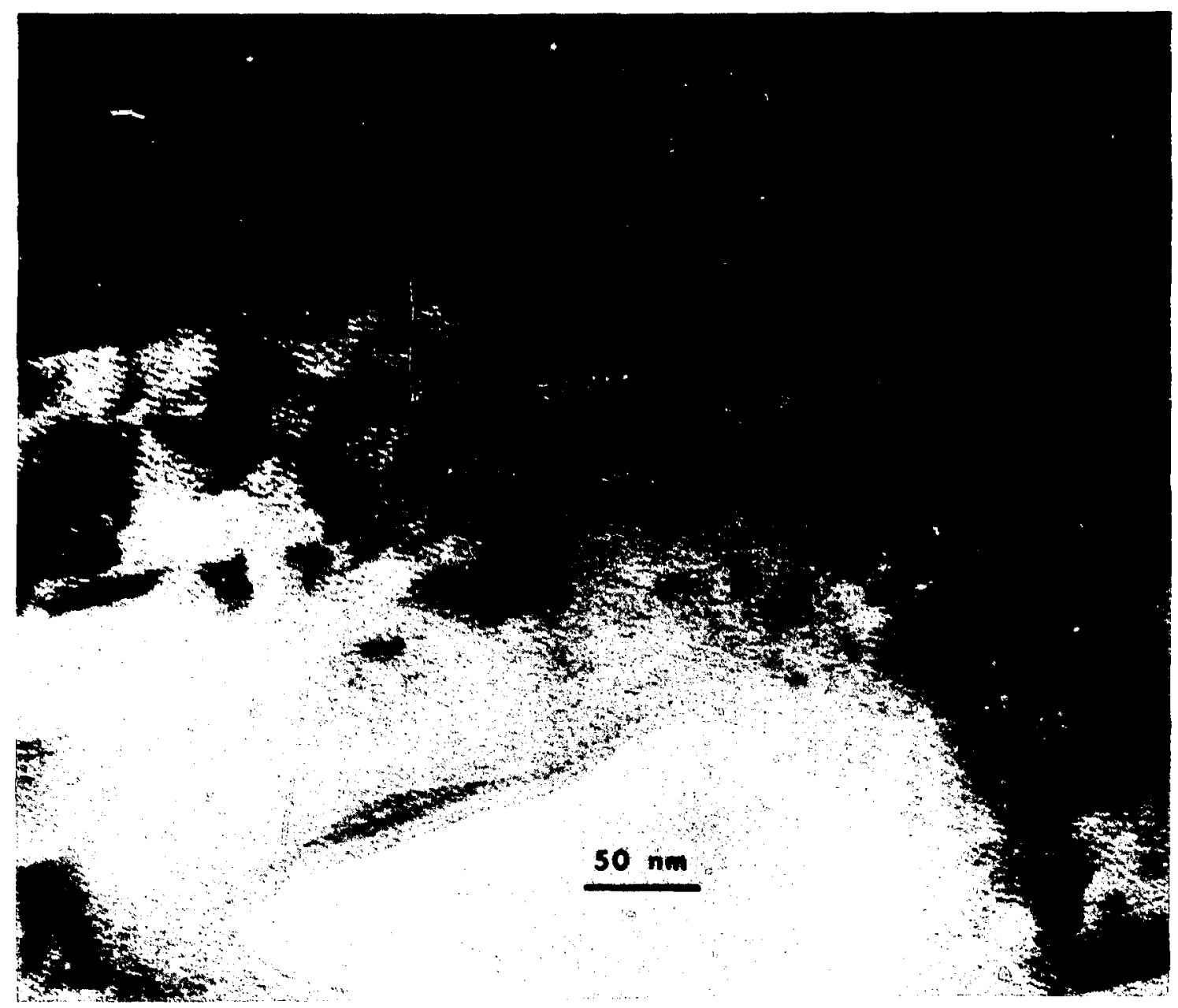

Fig. 5 Transmission Electron Micrograph of a Neutron-Irradiated $\left(550^{\circ} \mathrm{C}\right) \mathrm{Al}_{2} \mathrm{O}_{3}$ Single Crystal Material. The photo, shot near [27To] zone axis diffracting conditions, shows the small faults, or twins, which were found to exist everywhere in this material. $200 \mathrm{kV}$. 

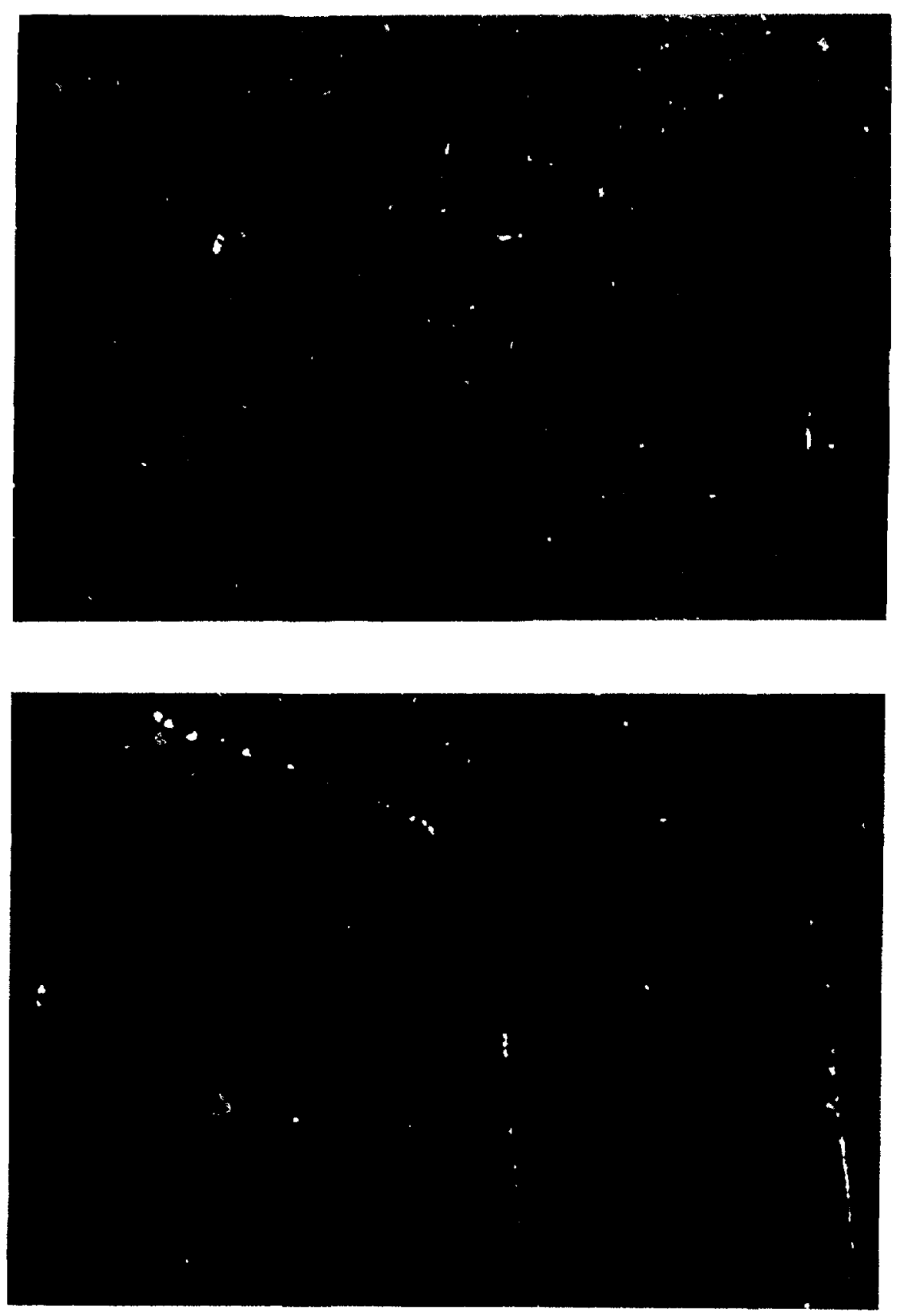

Fig. 6 Optical Micrographs of Some of the Samples of Irradiated $\mathrm{Al}_{203}$ (a. $400^{\circ} \mathrm{C}$, b. $550^{\circ} \mathrm{C}$ ). Note the brown coloration in all samples, resulting from some type of oxygen-vacancy defect created during irradiation. 

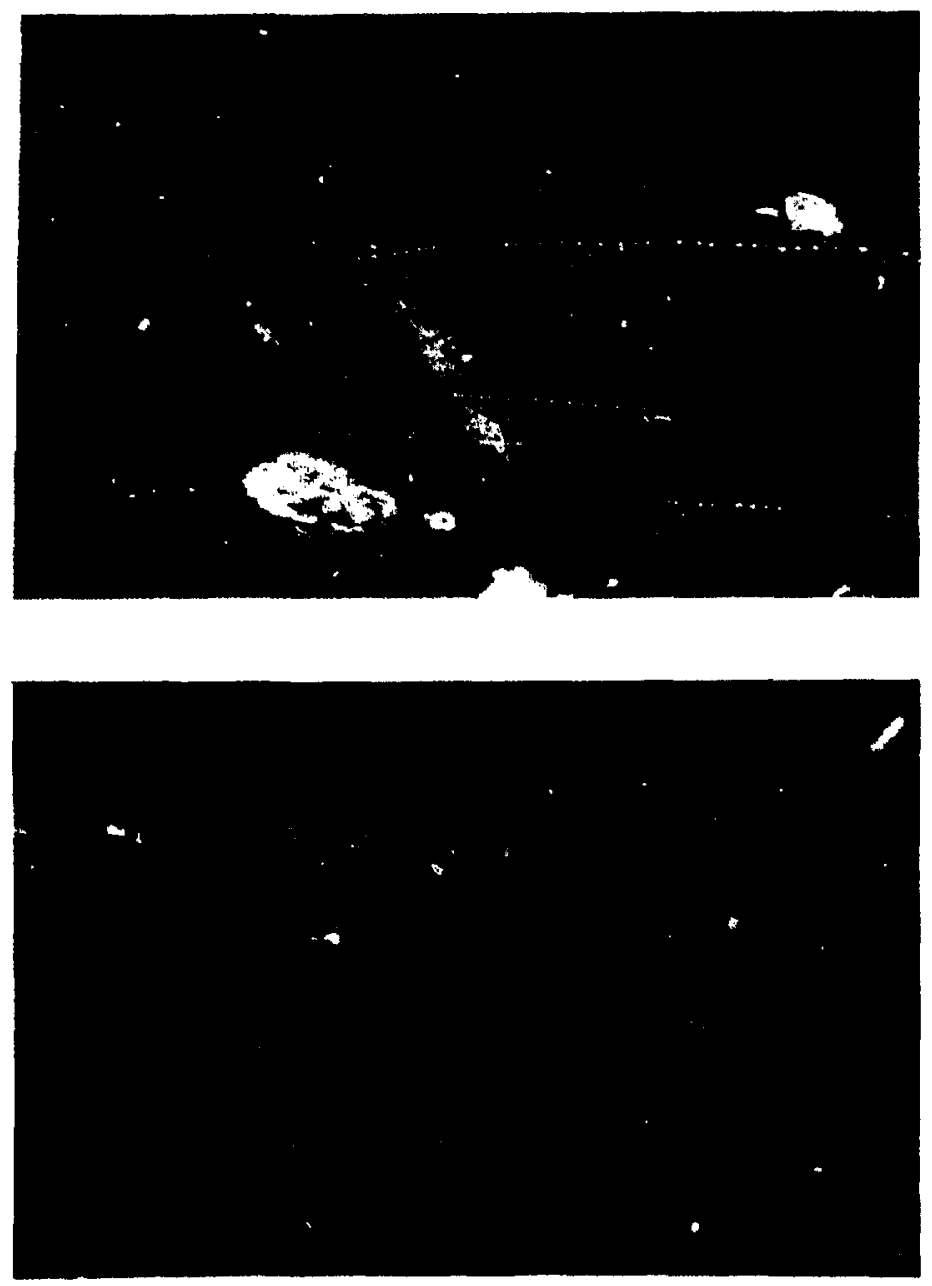

Fig. 7 Scanning Electron Micrographs of the Previously Optically-flat Surfaces of As-irradiated $\mathrm{Al}_{2} \mathrm{O}_{3}$. The arrowed features may be a bTistering effect. Examination of unirradiated material is needed to confirm this. 
$\underline{\mathrm{Mg0}}$

Examinations of the irradiated pure MgO single crystal material (supplied by $Y$. Chen, ORNL) have so far been limited to density, visual, and SEM examinations. The density results indicate that the material did swell slightly, and, as in the case of $\mathrm{Al}_{2} \mathrm{O}_{3}$, the low temperature irradiation seemed to cause a greater volume (density) change (see Table 4). Swelling

\section{Table 4 -- Mgu Density Change}

\begin{tabular}{|c|c|c|}
\hline$\Delta V / V_{0}, \%$ & $\mathrm{~T}_{\text {irr }},{ }^{\circ} \mathrm{C}$ & $\phi \mathrm{t}, 10^{22} \mathrm{n} / \mathrm{cm}^{2}$ \\
\hline 1.2 & 400 & 2.07 \\
\hline 0.9 & 550 & 2.13 \\
\hline
\end{tabular}

of Mgo has been observed previously in electron-irradiated material. ${ }^{7}$ The unusual features of that study was that, although MgO has a cubic crystal structure, the voids were not symmetric but seemed flattened. The investigators surmised that because the flattened direction was perpendicular to the TEM foil surface the phenomenon may be thin-section related. Our study should answer this question since our material was irradiated in the form of $\sim 3 \mathrm{~mm}$ cuboids. However, caution must be taken in comparing electron and neutron irradiation studies; $\mathrm{Krefft}^{8}$ has shown that the degree to which ionization damage is created produces widely different effects, even on swelling. In any event, the MgO has been shipped to 
Case Western Reserve University for TEM examination by R. A. Youngman, one of the investigators in the electron irradiation study.

Visual examinations showed that the transparent single crystal material turned opaque and black in reactor (see Fig. 8). It is not clear at this time whether a specific color center developed in the thick section or whether the opacity has resulted from partial reduction of the oxide in reactor. Cutting the samples to thin sections for TEM examination will help clarify this, as a color-center related effect should then show its color and translucency.

, SEM examinations of the surfaces showed no evidence of blistering, only revealing the small cleavage facts caused by specimen fabrication. The smoothly cleaved surfaces should have shown blisters if such a phenomenon had occurred.

Mechanical properties will not be measured for this material or the sirigle-crystal $\mathrm{Al}_{2} \mathrm{O}_{3}$. Much of this work has been done before for $\mathrm{Al}_{2} \mathrm{O}_{3},{ }^{9}$ and for $\mathrm{MgO}$ such properties would be of more interest if measured using polycrystalline material. Keilholz, et al ${ }^{10}$ and Ibrahim and Tangri ${ }^{11}$ have done some of these studies previously.

$\mathrm{SiO}_{2}$

Included in the experiment were both crystal $\alpha$-quartz and a dry, relatively pure silica glass (Infracil). The quartz was included as a minor basic study of a component material in many multi-phase ceramics, 


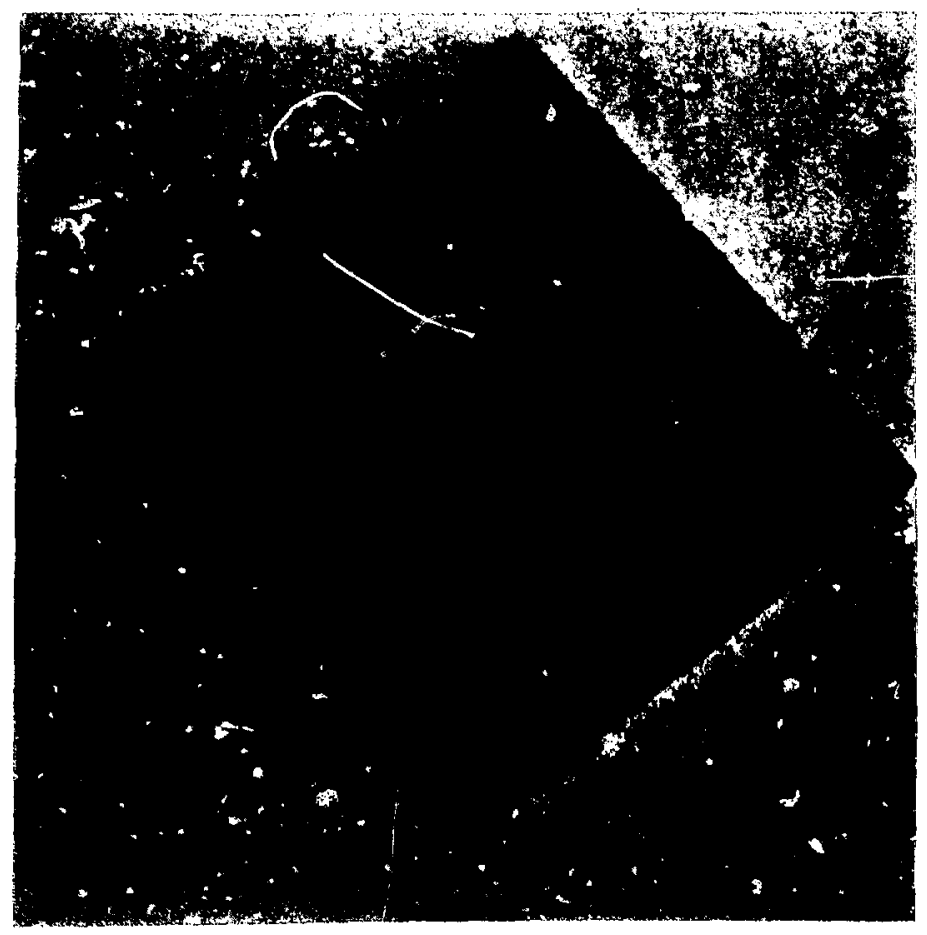

Fig. 8 Optical Micrograph of Irradiated $\left(550^{\circ} \mathrm{C}\right) \mathrm{MgO}$ Single Crystal. Note the dark coloration of the previously transparent material. 
and the Infracil was thought to be a possible window material. Dry silica has been shown to be more radiation-damage resistant as $\mathrm{OH}^{-}$ radical groups seem to form "nuclei" for further structural breakdown, especially in crystalline $\mathrm{SiO}_{2} \cdot{ }^{12}$

There are several excellent reviews on work done with irradiation damage in $\mathrm{SiO}_{2}{ }^{12}$ as well as in other structurally related ceramics. ${ }^{13}$ Leadbetter, et al ${ }^{13}$ found that ceramics with crystal structures similar to the crystalline forms of $\mathrm{SiO}_{2}$ were susceptible to irradiation-induced vitrification-type damage roughly in order of their degree of covalent bonding; materials with more ionic character were more resistant. Moreover, their work, as well as that of Primak ${ }^{14}$ and Katenkamp, et al ${ }^{15}$, indicate that the damage to vitreous silica, as measured by densification and increase in refractive index saturates at low neutron fluences $\left(10^{18}-10^{19} \mathrm{n} / \mathrm{cm}^{2}\right)$. In fact, these properties approach the same value for both heavily damaged quartz and vitreous silica. It appears then that properties measured after low dose irradiations can be easily used to approximate high dose effects. Our preliminary testing of highly irradiated Infracil indicates that in many cases this conclusion is true, but some results have indicated that high dose effects may appear unexpectedly. These results will be discussed in the following few paragraphs.

Table 5 shows the results of measured densification in Infracil. The results comparo almost exactly to the saturation in densification observed in EBR-II irradiated Supracil, another very pure, dry $\mathrm{SiO}_{2}$ material. In this study Primak ${ }^{14}$ found that densification was nearly 
Table 5 -- Infracil Density Change

\begin{tabular}{ccc}
$\Delta V / V_{0}, \%$ & $\frac{T_{\text {irr }},{ }^{\circ} \mathrm{C}}{400}$ & $\frac{\phi t, 10^{22} \mathrm{n} / \mathrm{cm}^{2}}{-1.4}$ \\
\hline-1.1 & 550 & 2.39 \\
400 & 2.48
\end{tabular}

constant at all exposures ( $1.2 \geq \phi t \geq 3.6,10^{21} \mathrm{n} / \mathrm{cm}^{2}$ total fluence) at an irradiation temperature of $370^{\circ} \mathrm{C}$, and that this densification was 1.59\%. Moreover, the refractive index increase had also saturated at these fluences, allowing the conclusion that a laser light measurement technique could be used in EBR-II using Supracil windows without serious transmission loss. Perhaps fortunately, the experimental equipment was never finished and installed, for our more highly irradiated material indicates that these "pure" silicas may be susceptible to forming a very unusual brown coloration at high fluences, as clearly seen in Fig. 9. It is not clear, however, at this time whether subtle differences in material, or the higher fluences, caused the effect, but if one wishes to utilize these materials as optical windows in an irradiation atmosphere, further investigations would be advised.

A very curious feature of the coloration is that it appears in the geometric center of the samples, equidistant from all free surfaces. The reason for this is difficult to explain for if an impurity is associated with the color, the diffusion distances needed to cause this effect, 

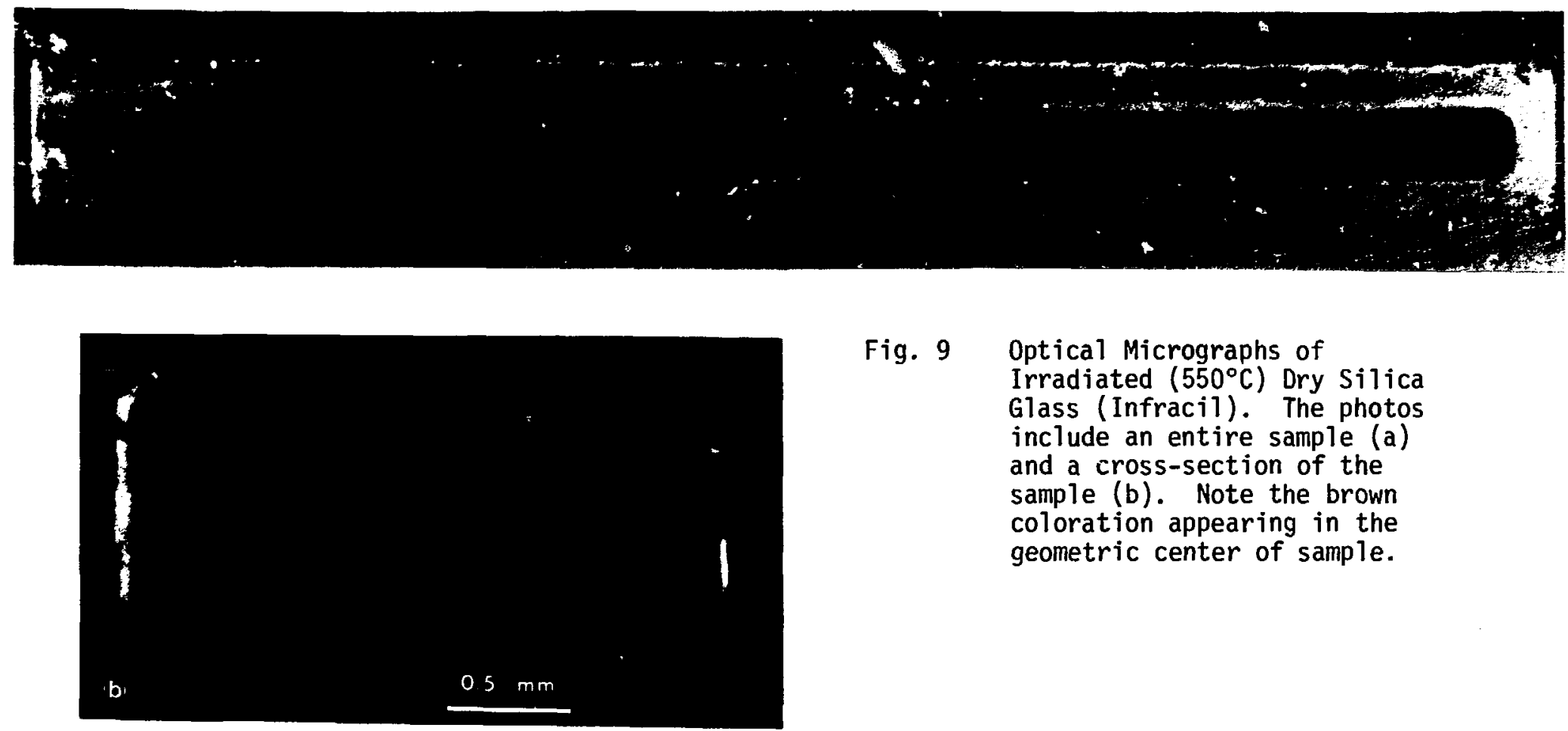

Fig. 9 Optical Micrographs of

Irradiated $\left(550^{\circ} \mathrm{C}\right)$ Dry Silica

Glass (Infracil). The photos

include an entire sample (a)

and a cross-section of the

sample (b). Note the brown

coloration appearing in the

geometric center of sample. 
$\sim 05 \mathrm{~mm}$, seem prohibitively large. TEM and STEM-EDAX examinations of the irradiated Infracil have indicated that the only unusual microstructural features were a few small particles of silicon metal contained within the glass. If this was the cause of the coloration, however, it would be expected that the near-surface regions would be more susceptible, not the interior. At the present, the phenomenon is unexplained.

Microhardness and thermal expansion have also been measured, as shown in Table 6 and Figs. 10, 11, and 12. The hardness increase is

\section{Table 6 -- Infracil Microhardness}

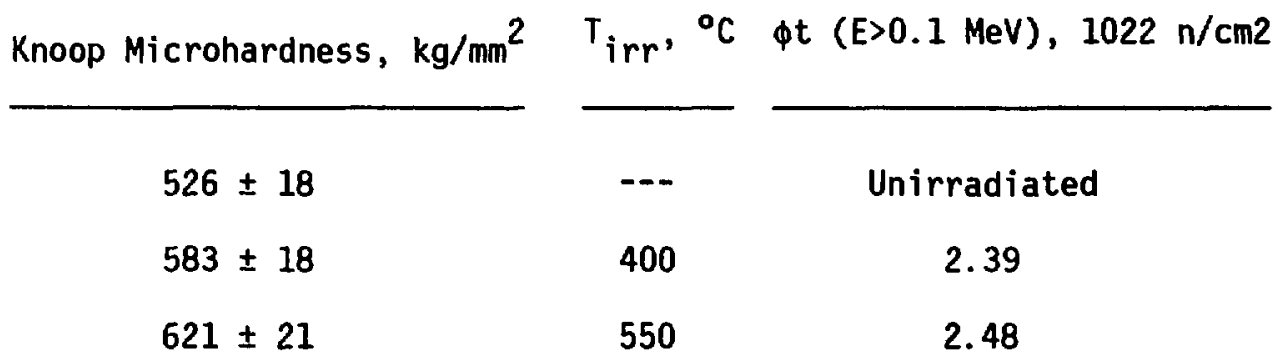

likely to be associated with the densification, and perhaps to the creation of some surface residual stresses, although Primak's study indicated no residual stress effects for irradiations at temperatures greater than $300^{\circ} \mathrm{C}$. Figures 10-12 show that the low thermal expansion exhibited by the Infracil was essentially unchanged by irradiation.

$\underline{H R 66 B}+\mathrm{COO}$ and MS011-A

Both HR66B + CoO and MS011-A are glass ceramics obtained from Sandia Laboratories (Bob Eagan, Sandy Lappin). They were alloy and chemically 


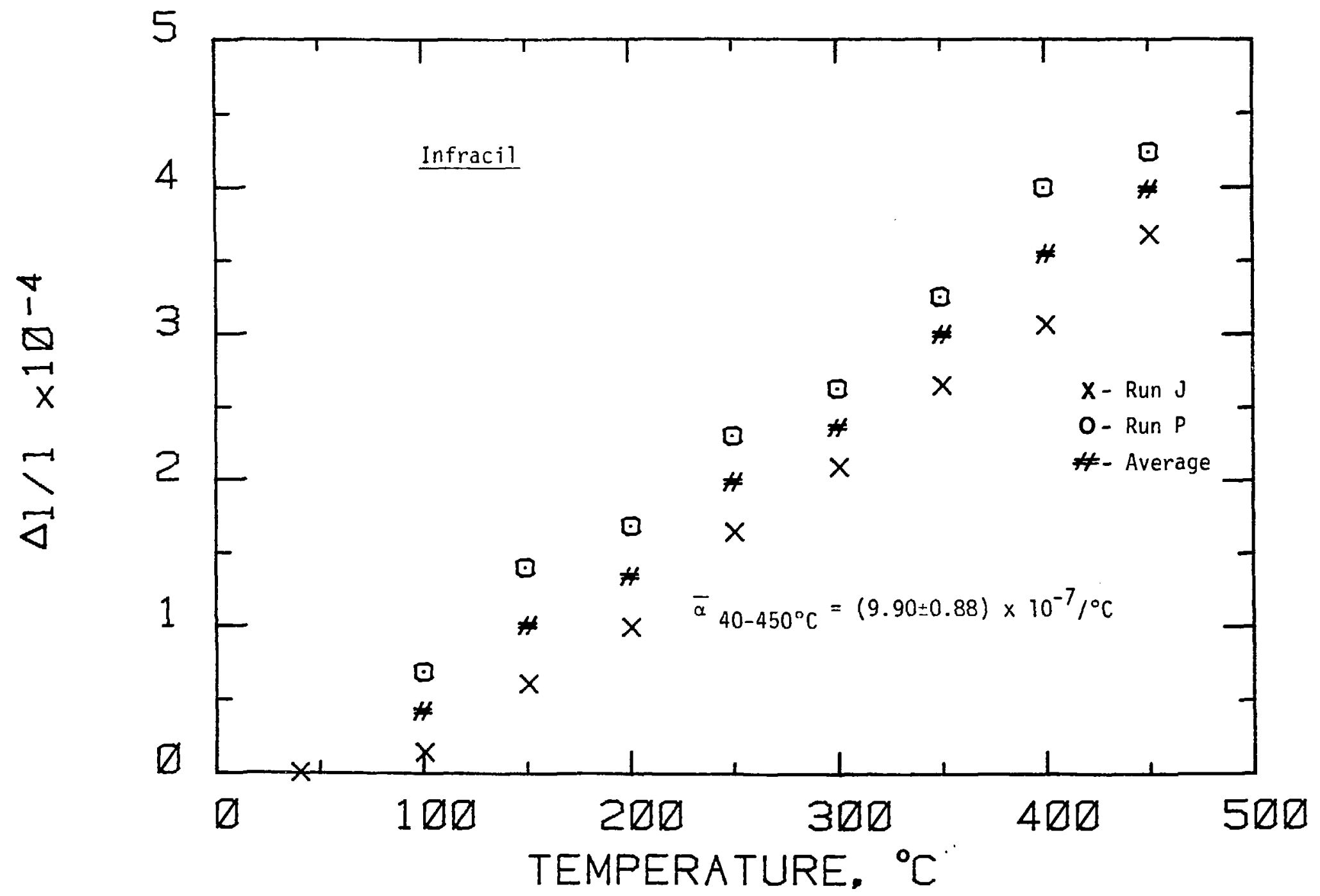

Fig. 10 Thermal Expansion Data for As-received Infracil Materiat. 


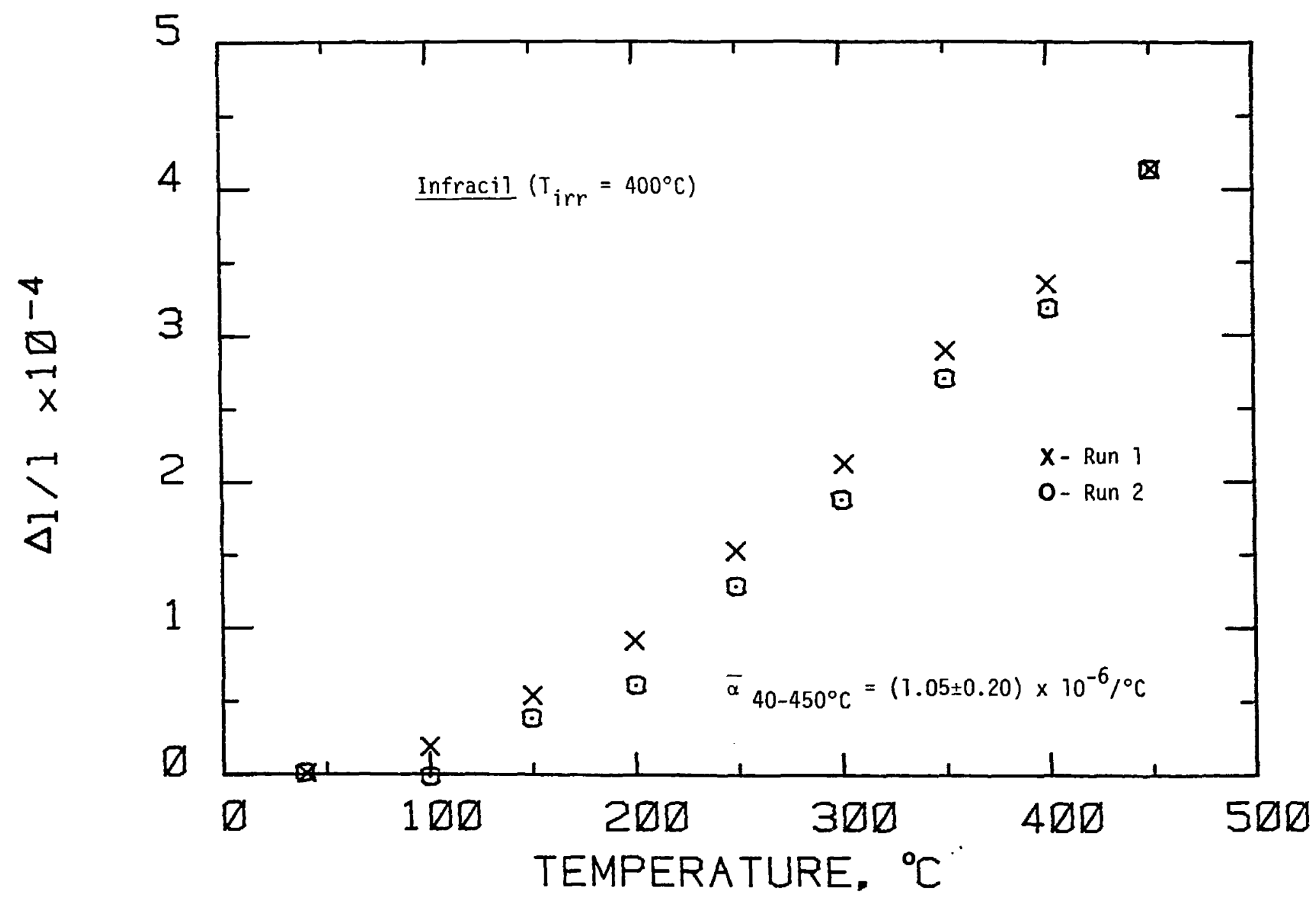

Fig. 11 Thermal Expansion Data for $400^{\circ} \mathrm{C}$ Neutron-irradiated Infracil. Note that within experimental accuracy the expansion coefficient (linear) is the same as that observed in unirradiated material. 


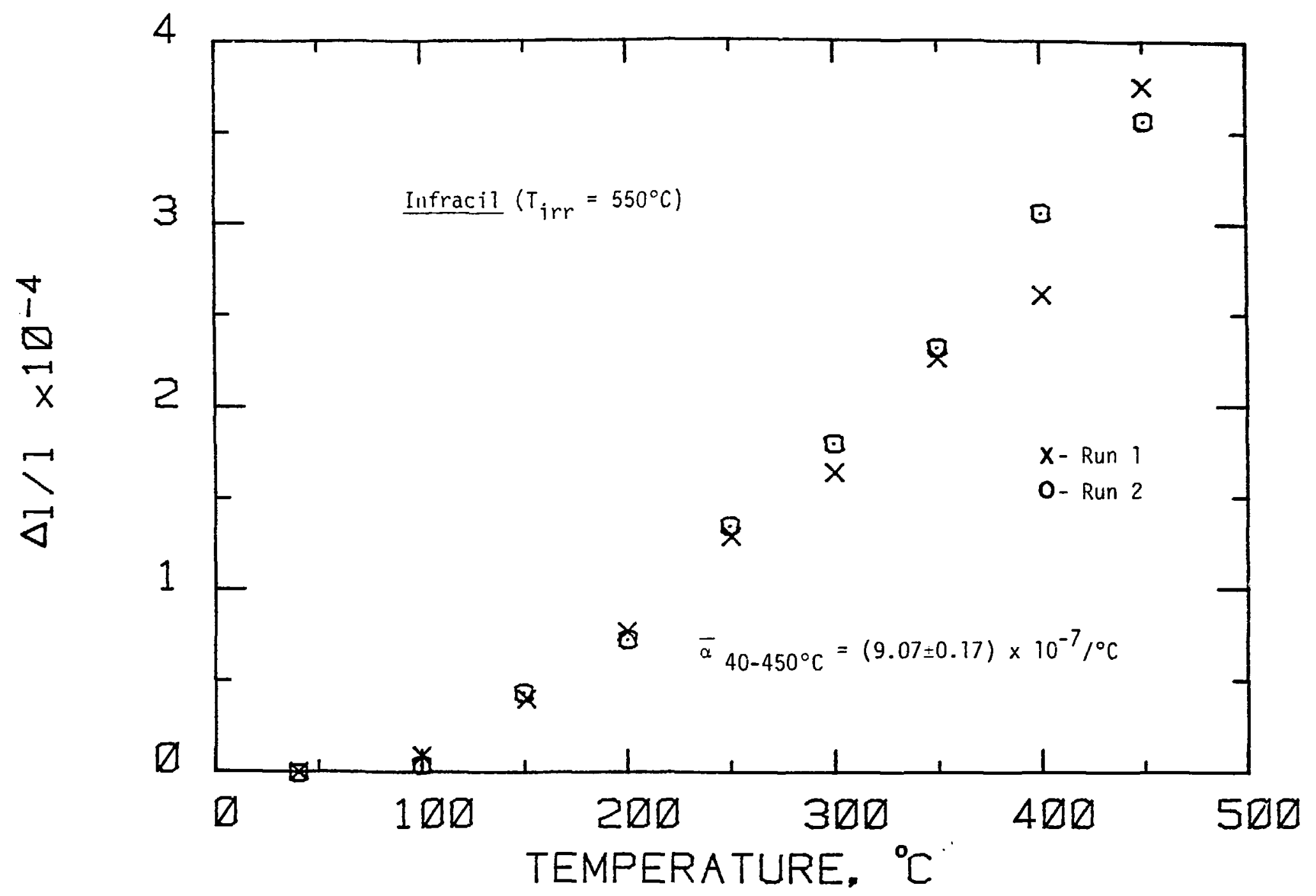

Fig. 12 Thermal Expansion Data for $550^{\circ} \mathrm{C}$ Neutron-irradiated Infracil. Note that within experimental accuracy the expansion coefficient (linear) is the same as that observed in unirradiated material. 
designed to match the thermal expansion behaviors of 300-series stainless steels and Mo respectively so that metal-ceramic bonds would not degrade under thermal cycling conditions. To date, because the materials formed some high-energy $\gamma$-radiation emitting activation products, only density changes have been measured for the materials.

The material's physical appearance was slightly darkened, the MS011-A being clear (glassy form) or white (ceramic) before irradiation, possibly due to a slight reduction of the oxide. All were apparently mechanically integrous, the samples showing no evidence of material loss.

The activation products most deleterious to handling of the materials were ${ }^{65} \mathrm{Zn}$ for MSO11-A and ${ }^{60} \mathrm{Co}$ for $\mathrm{HR} 66 \mathrm{~B}+\mathrm{CoO}$, both of which have long half-lives (245 days and 5.27 years, respectively). Figure 13 shows typical $\gamma$-scan results for the section of irradiated capsule containing the HR66B $+\mathrm{CoO}$. The ${ }^{54} \mathrm{Mn}$ and ${ }^{58} \mathrm{Co}$ traces clearly outline the 316 stainless steel density, as thase are the most prominent stainless steel activation products. The ${ }^{60}$ Co trace, however, shows increased intensity where the glass ceramic samples are located.

Table 7 illustrates the density changes associated with irradiation. The density changes showed very little effect for the HR66B $+\mathrm{CoO}$, with the exception that the $550^{\circ} \mathrm{C}$-irradiated ceramic material densified slightly. The MS011-A materials all approached a density of about $3.02 \mathrm{~g} / \mathrm{cm}^{3}$, indicating possibilities of some swelling and some crystallization of the glassy material. TEM examinations will confirm the causes for the density 
designed to match the thermal expansion behaviors of 300-series stainless steels and Mo respectively so that metal-ceramic bonds would not degrade under thermal cycling conditions. To date, because the materials formed some high-energy $y$-radiation emitting activation products, only density changes have been measured for the materials.

The material's physical appearance was slightly darkened, the MS011-A being clear (glassy form) or white (ceramic) before irradiation, possibiy due to a slight reduction of the oxide. All were apparently mechanically integrous, the samples showing no evidence of material loss.

The activation products most deleterious to handling of the materials were ${ }^{65} \mathrm{Zn}$ for MS011-A and ${ }^{60} \mathrm{Co}$ for HR66B $+\mathrm{CoO}$, both of which have long half-lives (245 days and 5.27 years, respectively). Figure 13 shows typical $\gamma$-scan results for the section of irradiated capsule containing the HR66B + CoO. The ${ }^{54} \mathrm{Mn}$ and ${ }^{58}$ Co traces clearly outline the 316 stainless steel density, as these are the most prominent stainless steel activation products. The ${ }^{60}$ Co trace, however, shows increased intensity where the glass ceramic samples are located.

Table 7 illustrates the density changes associated with irradiation. The density changes showed very little effect for the HR66B $+\mathrm{CoO}$, with the exception that the $550^{\circ} \mathrm{C}$-irradiated ceramic material densified slightly. The MSO11-A materials all approached a density of about $3.02 \mathrm{~g} / \mathrm{cm}^{3}$, indicating possibilities of some swelling and some crystallization of the glassy material. TEM examinations will confirm the causes for the density 


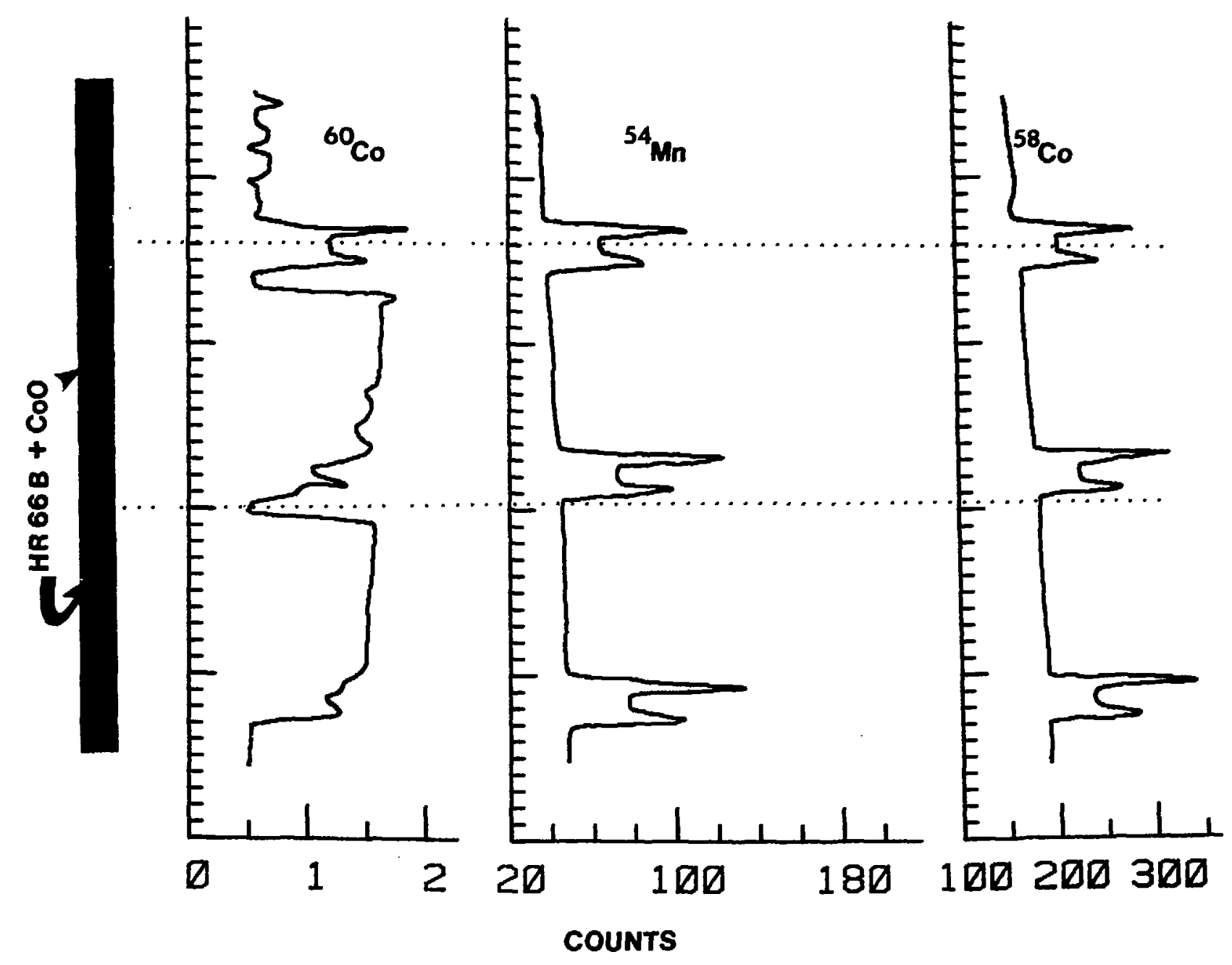

Fig. 13 - Scan Results of the Capsule Section Containing the HR66B + CoO Glass Ceramic. A Neutron Radiograph (7eft) Has Been Included for Reference. Nete that ${ }^{58}$ Co and ${ }^{54} \mathrm{Mn}$ Show Only the Stainless Steel Capsule Materia1, While the ${ }^{6}$ Co Trace Shows the Activation of the Ceramic. 
Table 7 -- Density Changes in HR66B + CoO and MSO11-A

\begin{tabular}{|c|c|c|c|}
\hline$\Delta V / V_{0}, x$ & $\mathrm{~T}_{\text {irr }},{ }^{\circ} \mathrm{C}$ & Ceramic Type & $\phi t(E>M e V), 10^{22} \mathrm{n} / \mathrm{cm}^{2}$ \\
\hline-0.05 & 400 & HR66B + Co0, glass & 2.21 \\
\hline+0.12 & 400 & HR66B + CoO, ceramic & 2.36 \\
\hline-1.20 & 550 & HR66B $+\mathrm{CoO}$, ceramic & 2.43 \\
\hline+2.60 & 400 & MS011-A, glass & 2.46 \\
\hline+0.74 & 400 & MS011-A, ceramic & 2.46 \\
\hline+0.83 & 550 & MS011-A, ceramic & 2.53 \\
\hline
\end{tabular}

changes. The density measurements used here were done in-cell, which could result in less accuracy; all others reported were done external to a hot cell.

Figures 14-17 illustrate the thermal expansion properties measured for the unirradiated materials. The irradiated materials have not yet been tested.

\section{ReX Glass Ceramic}

ReX is also a glass ceramic supplied by Sandia. It is a slightly modified form of a commercial product of the same name produced by General Electric. Its thermal expansion properties match that of some Inconel alloys. It did not form any serious activation products in EBR-II and could therefore be easily studied. We have characterized the as-irradiated 


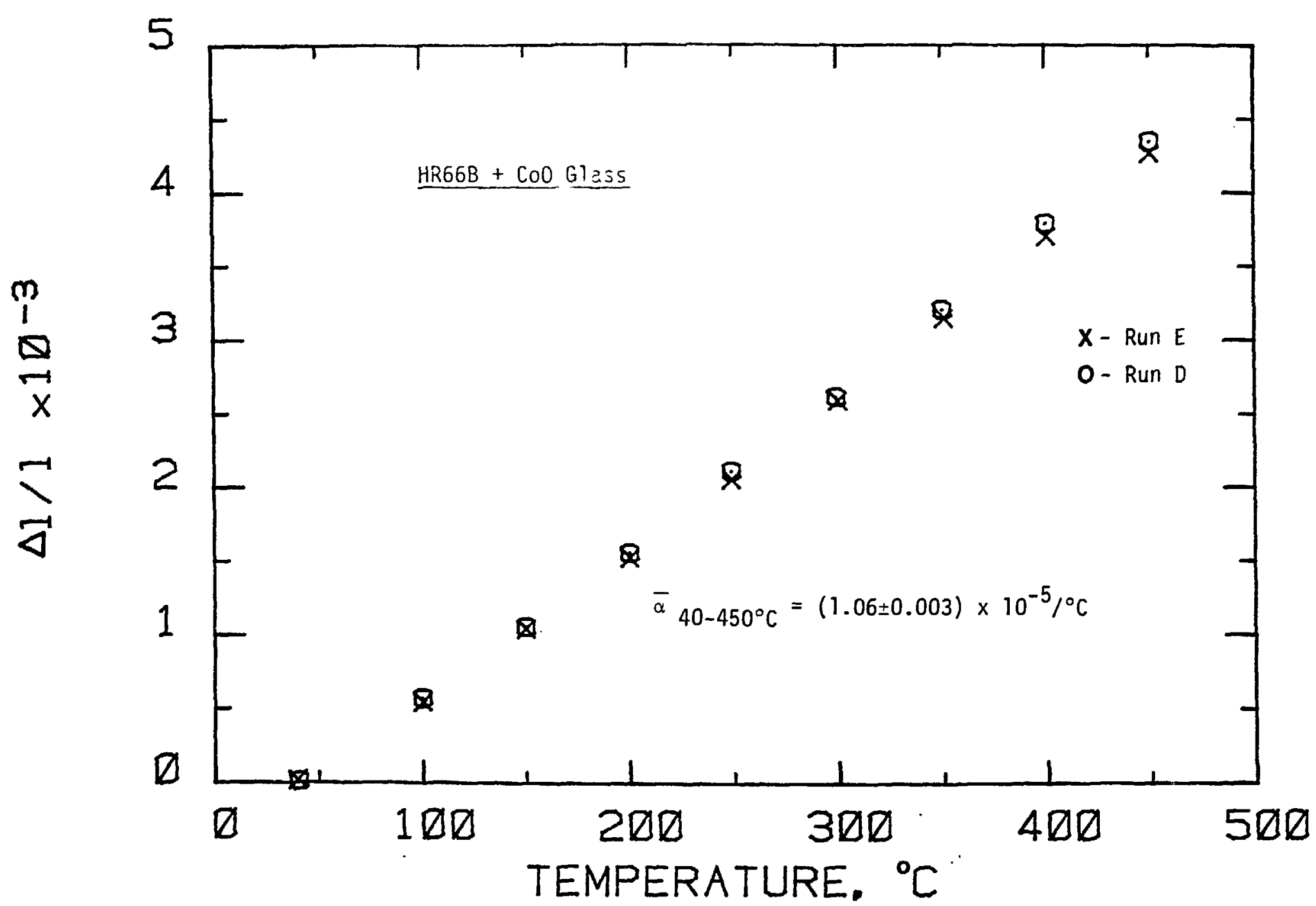

Fig. 14 Thermal Expansion Data for Unirradiated HR66B + Co0 Glass Ceramic (g7assy form) 


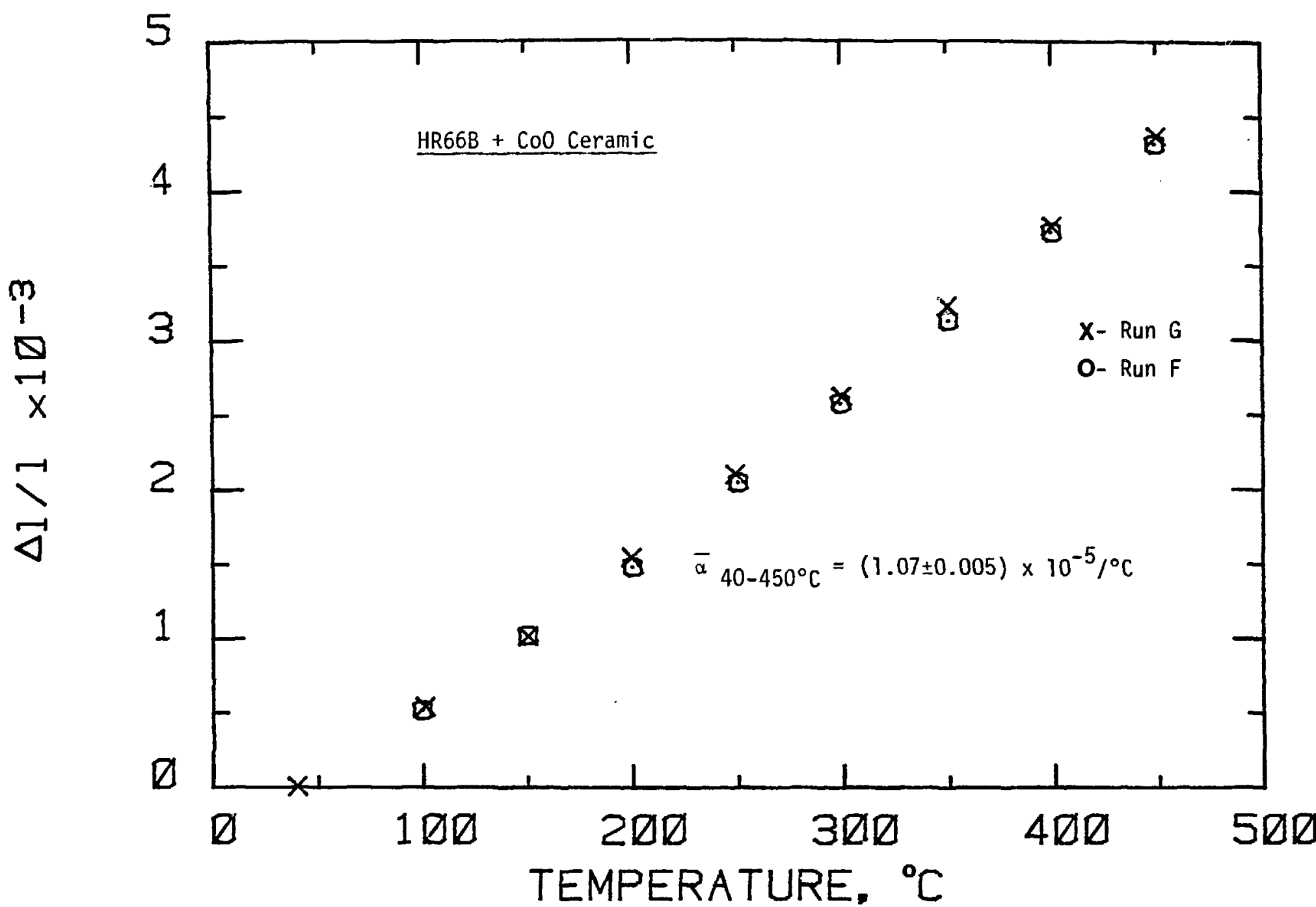

Fig. 15 Thermal Expansion Data for Unirradiated HR66B + CoO Glass Ceramic (ceramic form) 


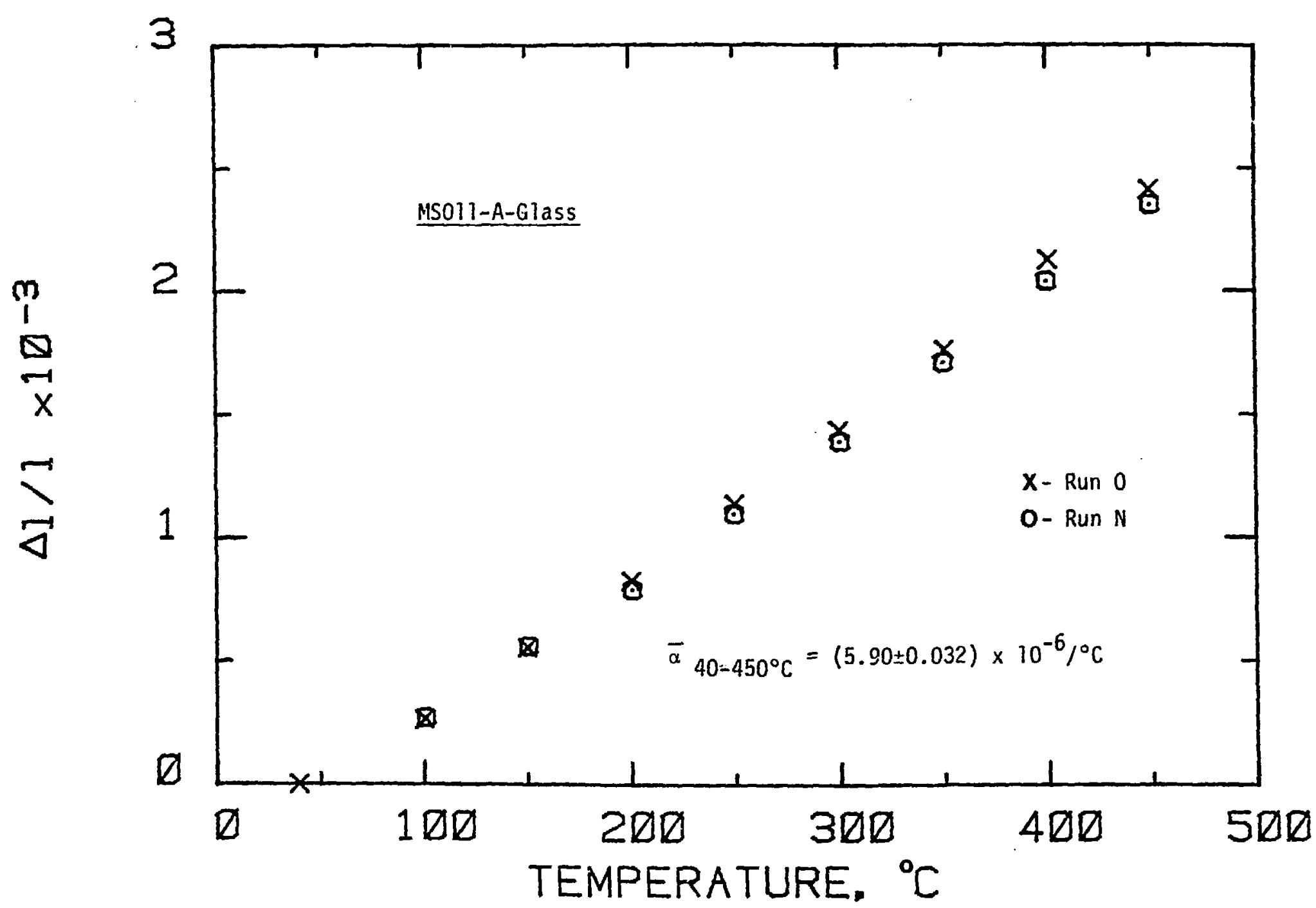

Fig. 16 Thermal Expansion Data for Unirradiated MS011-A Glass Ceramic (glassy form) 


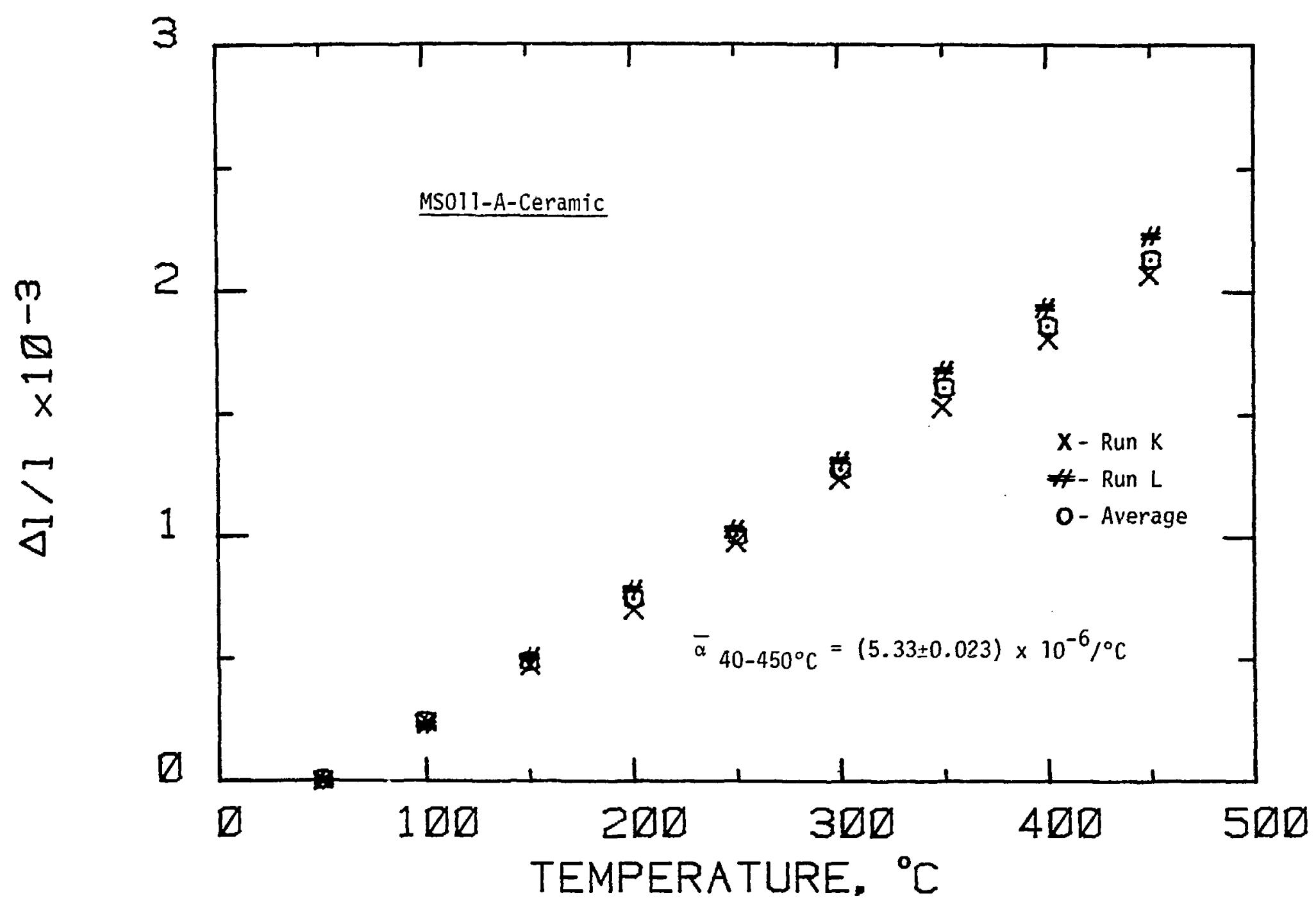

Fig. 17 Thermal Expansion Data for Unirradiated MSO11-A Glass Ceramic (ceramic form) 
materials as to density, hardness, fracture toughness, thermal expansion, and TEM microstructural analysis.

As with the other glass ceramics and the MgO, the irradiated ReX appeared gray in color, possibly the result of some oxide reduction. In handling, the ReX appeared to have retained at least measurable mechanical properties. Both hardness and fracture toughness were measured and are presented in Table 8 . The microhardness results show that both the glassy form and the partially ceramic form appeared to be irradiation hardened. This is most likely, because the surfaces were ground and polished before testing. However, if residual surface stresses were induced to enough depth so that the polishing did not remove them, then this could also be a reason for increased hardness.

Table 8 -- Hardness and Fracture Toughness of ReX

\begin{tabular}{|c|c|c|c|c|}
\hline Hardness, $\mathrm{kg} / \mathrm{mm}^{2}$ & Material Form & $\mathrm{T}_{\mathrm{irr}},{ }^{\circ} \mathrm{C}$ & $\phi \mathrm{t}, 10^{22} \mathrm{n} / \mathrm{cm}^{2}$ & $K_{c}, M N / m^{3 / 2}$ \\
\hline $470 \pm 17$ & Glass & -- & --- & $N / A^{*}$ \\
\hline $527 \pm 33$ & Glass & 400 & 2.24 & $0.96 \pm 0.10$ \\
\hline $574 \pm 22$ & Glass & 550 & 2.33 & $1.16 \pm 0.09$ \\
\hline $544 \pm 14$ & Ceramic & $\cdots$ & $-\infty$ & $2.08 \pm 0.08$ \\
\hline $575 \pm 28$ & Ceramic & 400 & 2.02 & $1.12 \pm 0.09$ \\
\hline $624 \pm 34$ & Ceramic & 550 & 2.07 & $1.49 \pm 0.10$ \\
\hline
\end{tabular}

* Hertzian cone fractures prevented analysis 
The fracture toughness results support the fact that the ReX materials were irradiation hardened, because the microtechnique used to measure fracture toughness should also have shown an apparent increase in toughness if surface compressive residual stresses had been present. In contrast, the fracture toughness of the ceramic form was reduced considerably, despite the increased hardness.

Possible surface degradation (chips on corners, etc.) precluded doing reliable bend strength testing. However, if we assume that, because strength and fracture toughness are related by

$$
k_{c} \propto \sigma_{f} \sqrt{a_{c}}
$$

where $\sigma_{f}$ is the material's strength and $a_{c}$ is the critical flaw size, the fracture strength probably degraded proportionally to the fracture toughness. This would be true if there were no increase in $a_{c}$, a presumption we assume to be true unless severe microcracking had resulted from the irradiation; no such cracking was observed in the transmission electron microscopic examinations. A significant decrease in $a_{c}$ is at least equally unlikely.

Density changes are outlined in Table 9. The results show that there was very little change in density $(\leq 1 \%)$, and the densities themselves tended to approach a value of $\sim 2.36 \mathrm{~g} / \mathrm{cm}^{2}$, the preirradiated ceramic density being $\sim 2.39 \mathrm{~g} / \mathrm{cm}^{2}$ and the glass being $\sim 2.35 \mathrm{~g} / \mathrm{cm}^{2}$. This indicates that some vitrification may have occurred in the ceramic and some crystallization in the glass. However, the microscopic examinations do not confirm this, as this will be discussed in the next few paragraphs. 


\section{Table 9 -- ReX Density Changes}

\begin{tabular}{|c|c|c|c|}
\hline$\Delta V / V_{0}, x$ & Material Form & $\mathrm{T}_{\text {irr }},{ }^{\circ} \mathrm{C}$ & $\phi \mathrm{t}, 10^{22} \mathrm{n} / \mathrm{cm}^{2}$ \\
\hline-0.41 & Glass & 400 & 2.24 \\
\hline-0.74 & Glass & 550 & 2.33 \\
\hline+0.76 & Ceramic & 400 & 2.02 \\
\hline+1.01 & Ceramic & 550 & 2.07 \\
\hline
\end{tabular}

Transmission electron microscopic examinations of the ceramic material showed that the lithium silicate crystal phase survived the high-dose neutron irradiation (see Fig. 18). Moreover, the matrix glassy material, as well as the cyrstalline phase, showed no sign of swelling. The glass material showed a similar lack of microstructural change. A more detailed quantitative study comparing percent crystalline phase of irradiated and unirradiated materials is needed before it can be completely ruled out that the density change was caused by the loss of some of the crystalline phase.

Two very unusual effects were observed during the TEM examinations, both of which are very significant to the idea of using electron irradiation simulation of neutron effects in these materials. Firstly, the lithium silicate crystalline phase, apparently stable to the neutron bombardment, became glassy almost immediately ( $\leq 2$ minutes) upon exposure to a fairly intense $200 \mathrm{kV}$ electron beam. This vitrification, as clearly illustrated 


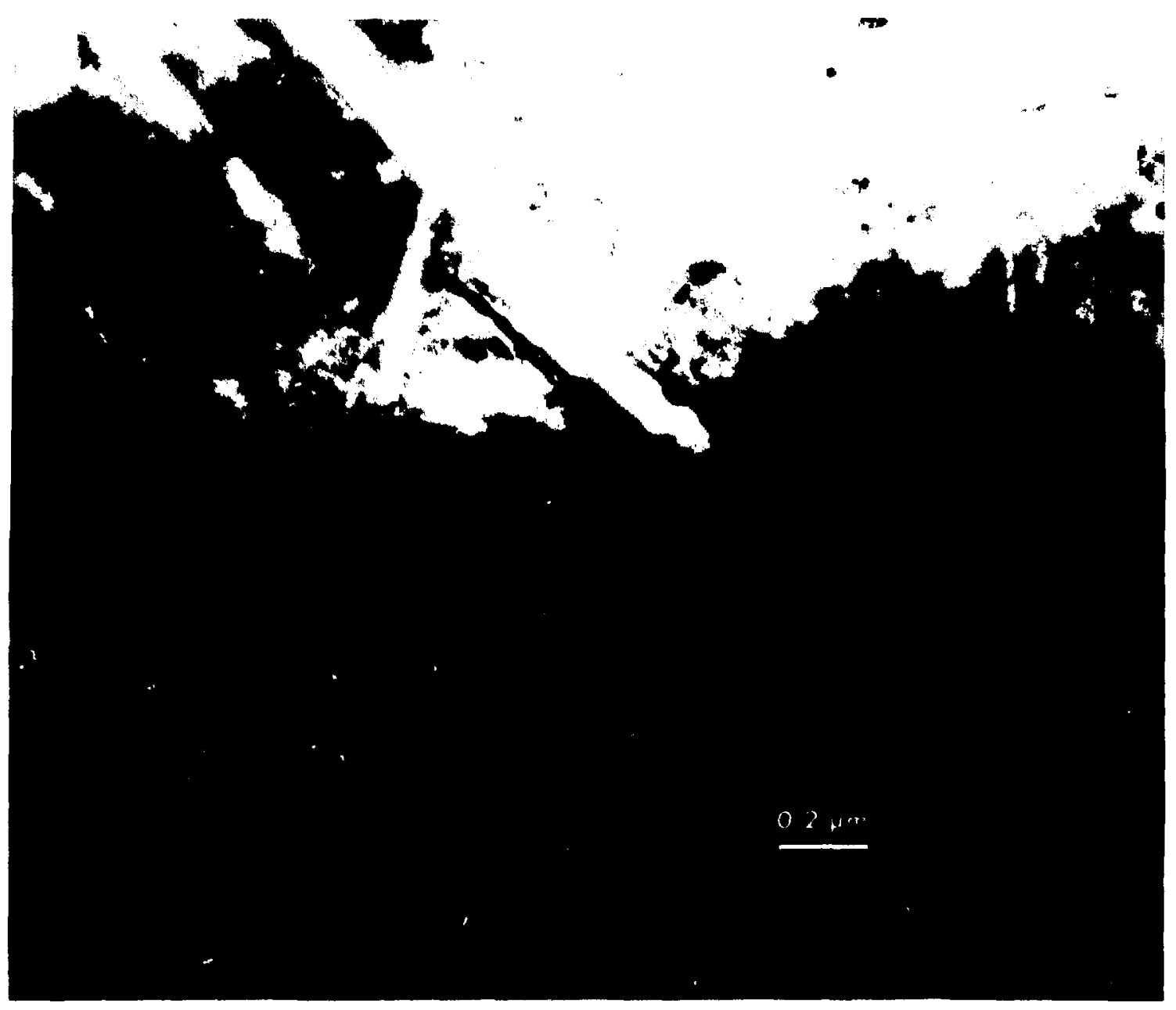

Fig. 18 Transmission Electron Micrograph of $550^{\circ} \mathrm{C}$ Neutron-irradiated ReX Glass Ceramic (ceramic form). The needle-like features are the lithium silicate crystal phase. $200 \mathrm{kV}$. 
in the TEM micrographs of Fig. 19, occurred within all crystallites leaving no crystalline phase where the electron beam had been after only a few minutes of exposure. This clearly demonstrates the degree to which ionization damage, as created by the electrons, may differ from the displacement damage that the fast neutrons create. Moreover, it points out that although simulation may be an effective method of producing neutron irradiation effects, there must at least be confirmative evidence from neutron experiments to assess whether the same type of damage phenomena occur.

This point is strengthened by the second unusual observation in doing the TEM analyses. As seen in Fig. 19c, there appear to be lightly colored bubble-like features in the material. Moreover, these features are not evident in the first figure 19 a) photo in the time series. The bubbles, or voids, have grown in the glassy phase as a result of the electron exposure. This effect is even more clear in a time series of micrographs taken of the irradiated glassy-form of the ReX (Fig. 20, a-f). The initial photcs in this series came out in poor focus so Fig. 20 does not clearly illustrate that the as-neutron-irradiated material was free of voids (bubbles). This fact was difficult to document because the bubbles grew so fast initially, even when the accelerating voltage was decreased to $100 \mathrm{kV}$. Figure 20 , however, does show that the bubbles (voids) do increase in size with time, coalesce to form larger bubbles, and finally shrink away, their contents (gas or vacancies) apparently diffusing to the foil's free surfaces. 

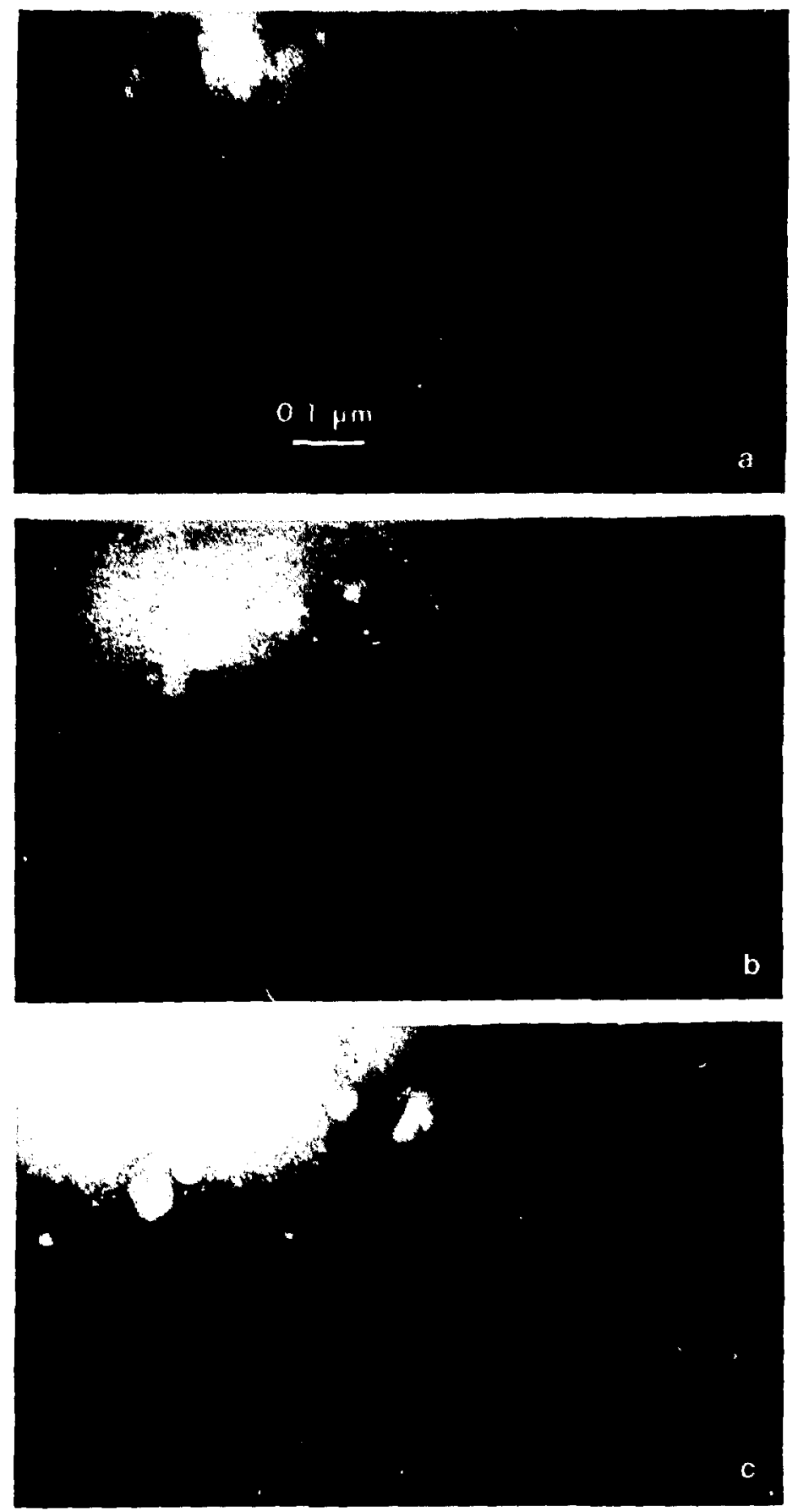

Fig. 19 Transmission Electron Micrographs of Neutron-irradiated ReX Showing Vitrification of the Lithium Silicate in the Electron Beam. Photos were taken at 245 second intervals. Vitrification was complete (c) in less than 2 minutes. $200 \mathrm{kV}$. 

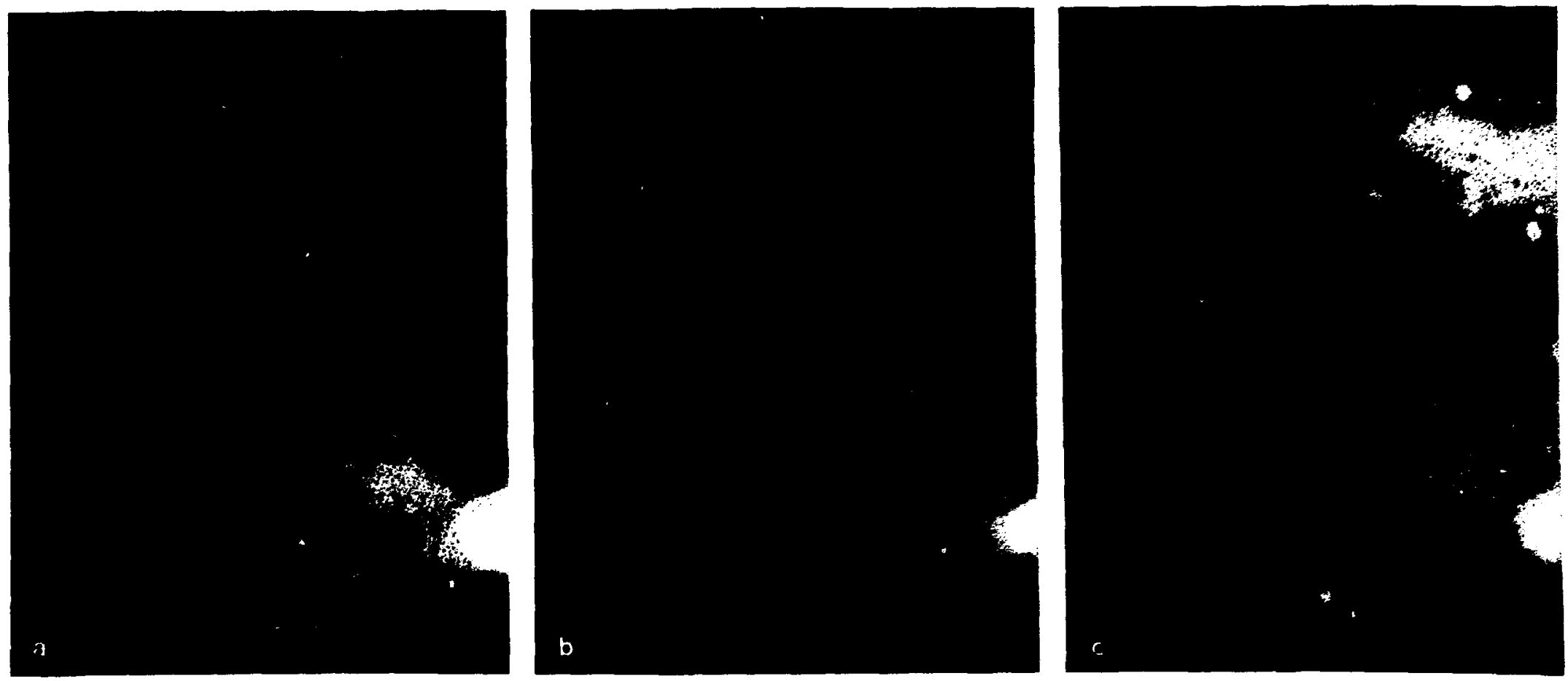

Fig. 20 (a-c) Time Sequence Electron Micrographs Showing "Bubble (void)" Formation in As-neutron-irradiated ReX (glassy form). The electron irradiation causes the void (bubble) formation. a) $4 \mathrm{~m} 40 \mathrm{~s}$; b) $6 \mathrm{~m} 40 \mathrm{~s}$; 3) $9 \mathrm{~m} .100 \mathrm{kV}$. 

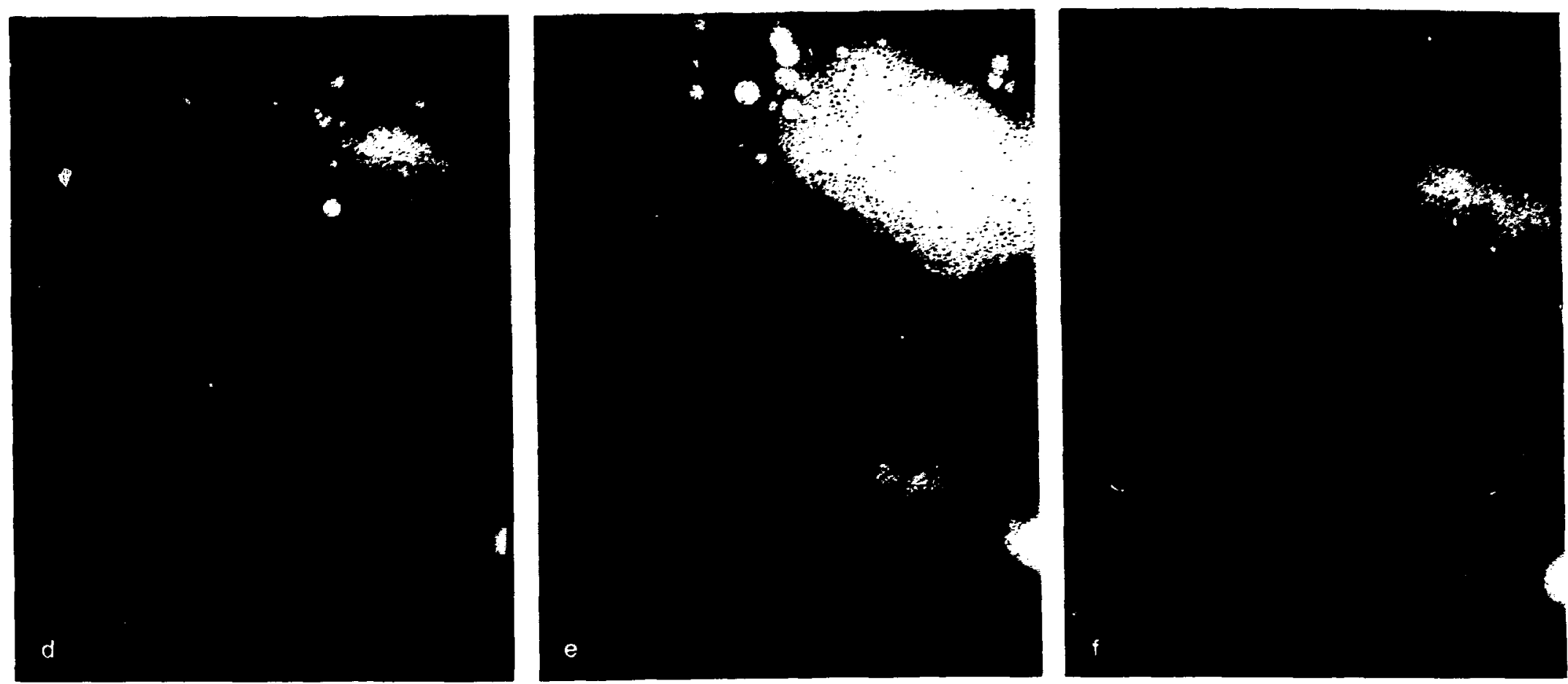

Fig. 20 (d-f) Time Sequence Electron Micrographs Showing "Bubble (void)" Formation in As-neutron-irradiated ReX (glassy form). The electron irradiation calises the void (bubble) formation. d) $15 \mathrm{~m}$; e) $25 \mathrm{~m} ;$ f) $40 \mathrm{~m}$. $100 \mathrm{kV}$. 
The entire process occurs so rapidly that intuitive explanations are difficult. It may be that neutron-irradiation induced defects, such as vacancies, or gas atoms resulting from $H e$ and ${ }^{3} T$ production from the small content of ${ }^{6} \mathrm{Li}$ in the ReX, are in solution in the ReX following EBR-II irradiation. The subsequent electron irradiation then stimulates defect migration and precipitation into larger microstructural features which eventually "sinter" away.

A piece of irradiated ReX glass was bombarded with a $10 \mathrm{kV}$ electron beam in our Auger system, where the ultra-high vacuum allows very sensitive gas analysis. No gas production was observed by this method, indicating that either the defects are voids (vacancy created), or that the $10 \mathrm{kV}$ electron beam was insufficient to create the effect. TEM exposure of unirradiated glassy ReX shows the same effect but at a much lower rate. A plausible explanation is that the effect is created by electronirradiation accelerated annealing of a high temperature, or defected, structure. The phenomenon further demonstrates the sharp contrasts in observed radiation damage caused by electron and neutron bombardment.

The thermal expansion of the ReX materials (Figs. 21-26) was not found to change significantly upon irradiation in EBR-II. This is an important result if the use of the material requires matching of its thermal expansion properties to an Inconel material to which it has been bonded. 
The entire process occurs so rapidly that intuitive explanations are difficult. It may be that neutron-irradiation induced defects, such as vacancies, or gas atoms resulting from $\mathrm{He}$ and ${ }^{3} \mathrm{~T}$ production from the small content of ${ }^{6} \mathrm{Li}$ in the $\operatorname{ReX}$, are in solution in the $\operatorname{ReX}$ following EBR-II irradiation. The subsequent electron irradiation then stimulates defect migration and precipitation into larger microstructural features which eventually "sinter" away.

A piece of irradiated ReX glass was bombarded with a $10 \mathrm{kV}$ electron beam in our Auger system, where the ultra-high vacuum allows very sensitive gas analysis. No gas production was observed by this method, indicating that either the defects are voids (vacancy created), or that the $10 \mathrm{kV}$ electron beam was insufficient to create the effect. TEM exposure of unirradiated glassy ReX shows the same effect but at a much lower rate. A plausible explanation is that the effect is created by electronirradiation accelerated annealing of a high temperature, or defected, structure. The phenomenon further demonstrates the sharp contrasts in observed radiation damage caused by electron and neutron bombardment.

The thermal expansion of the ReX materials (Figs. 21-26) was not found to change significantly upon irradiation in EBR-II. This is an important result if the use of the material requires matching of its thermal expansion properties to an Inconel material to which it has been bonded. 


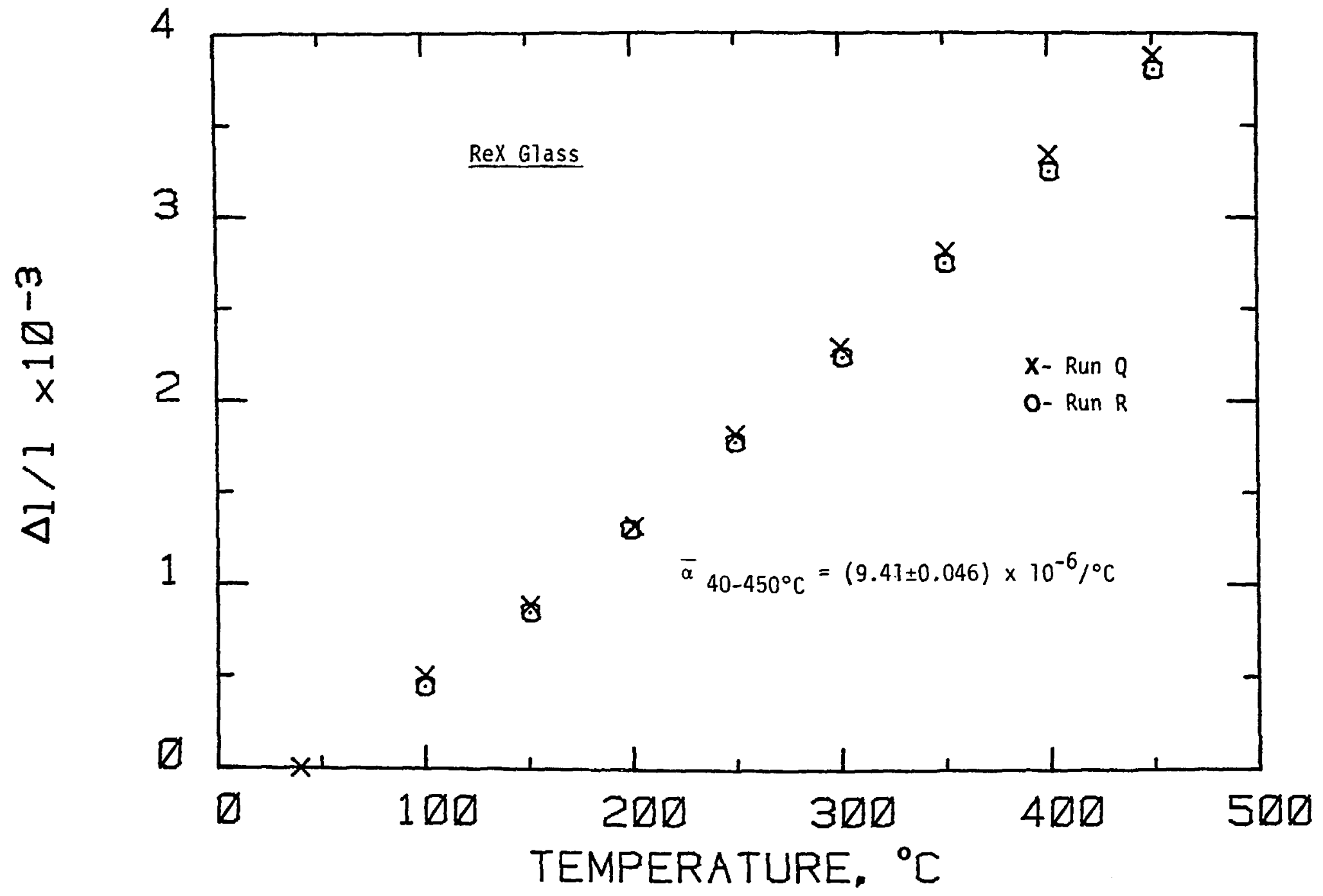

Fig. 21 Thermal Expansion Data for Unirradiated ReX Glass Ceramic (glassy form) 


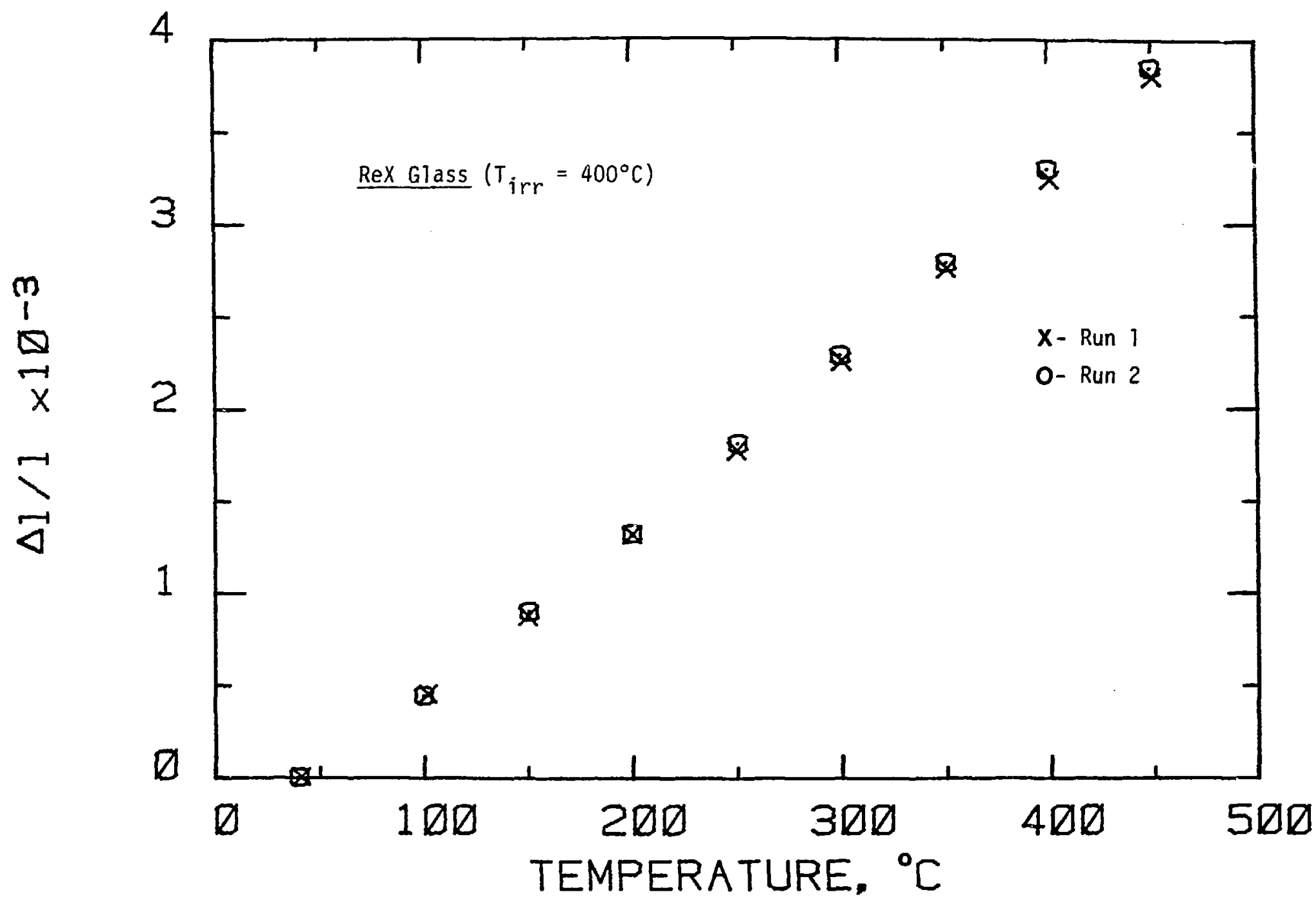

Fig. 22 Thermal Expansion Data for $400^{\circ} \mathrm{C}$ Neutron-irradiated ReX Glass Ceramic (glassy form) 


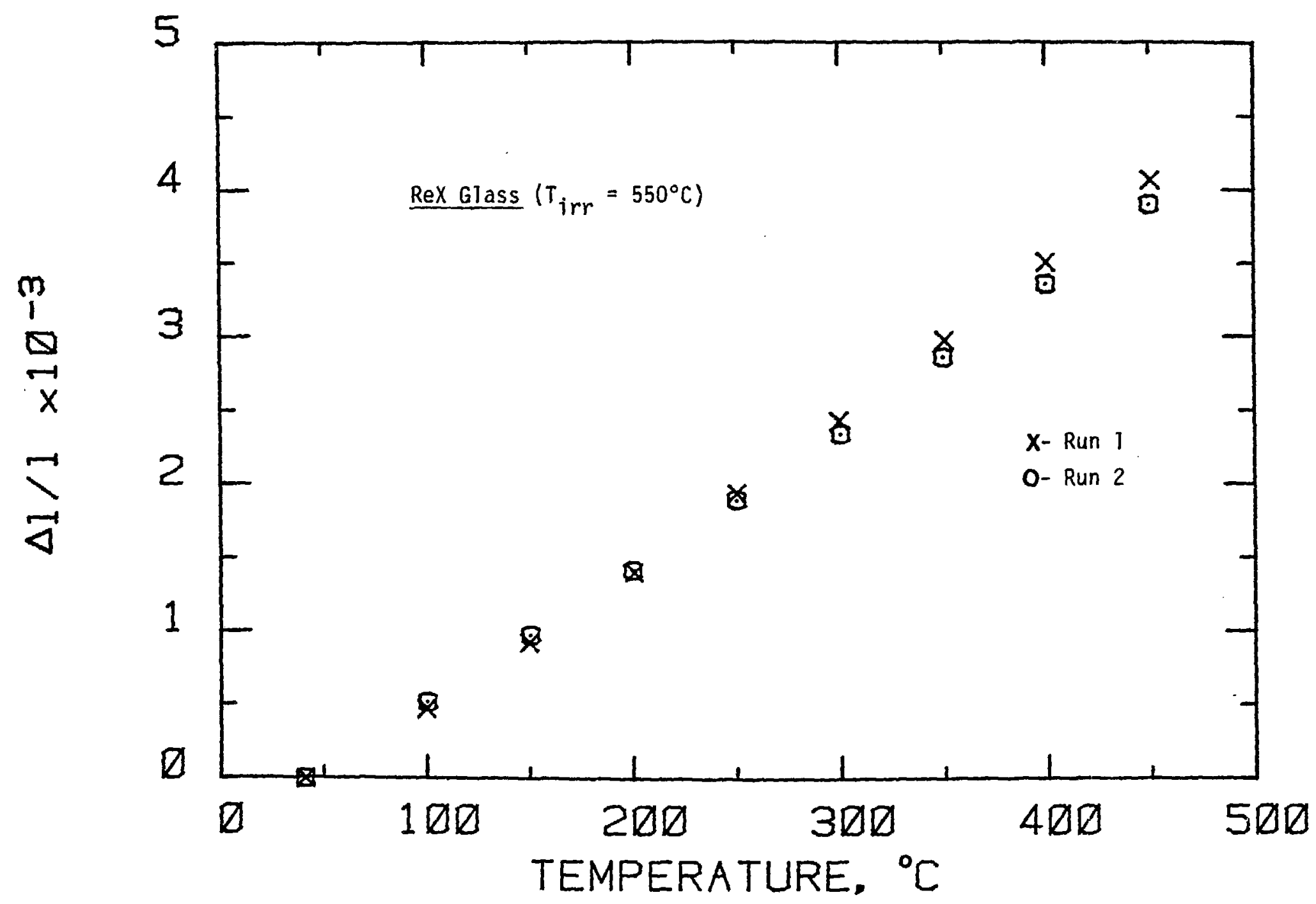

Fig. 23 Thermal Expansion Data for $550^{\circ} \mathrm{C}$ Neutron-irradiated ReX Glass Ceramic (glassy form) 


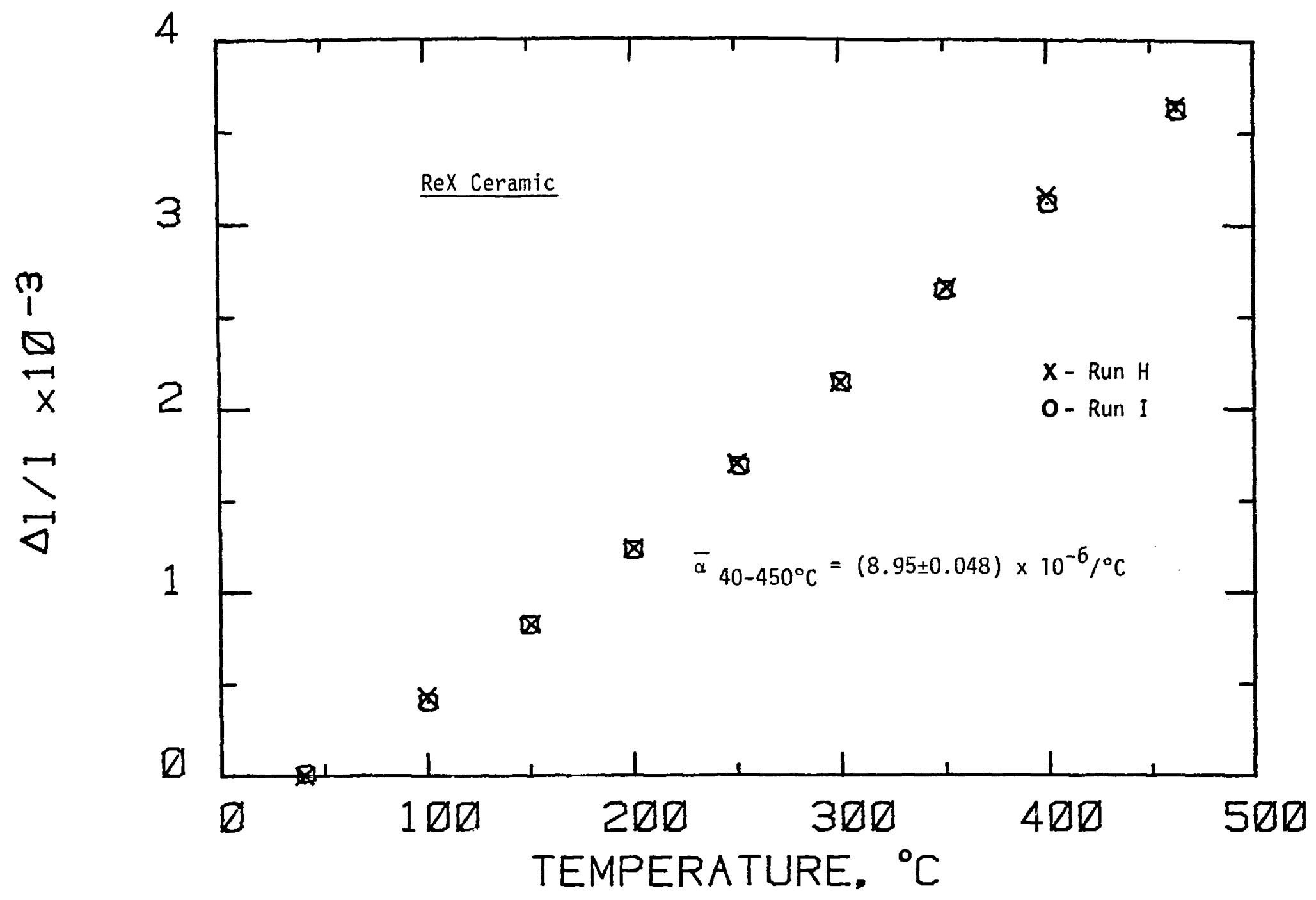

Fig. 24 Thermal Expansion Data for Unirradiated ReX Glass Ceramic (ceramic form) 


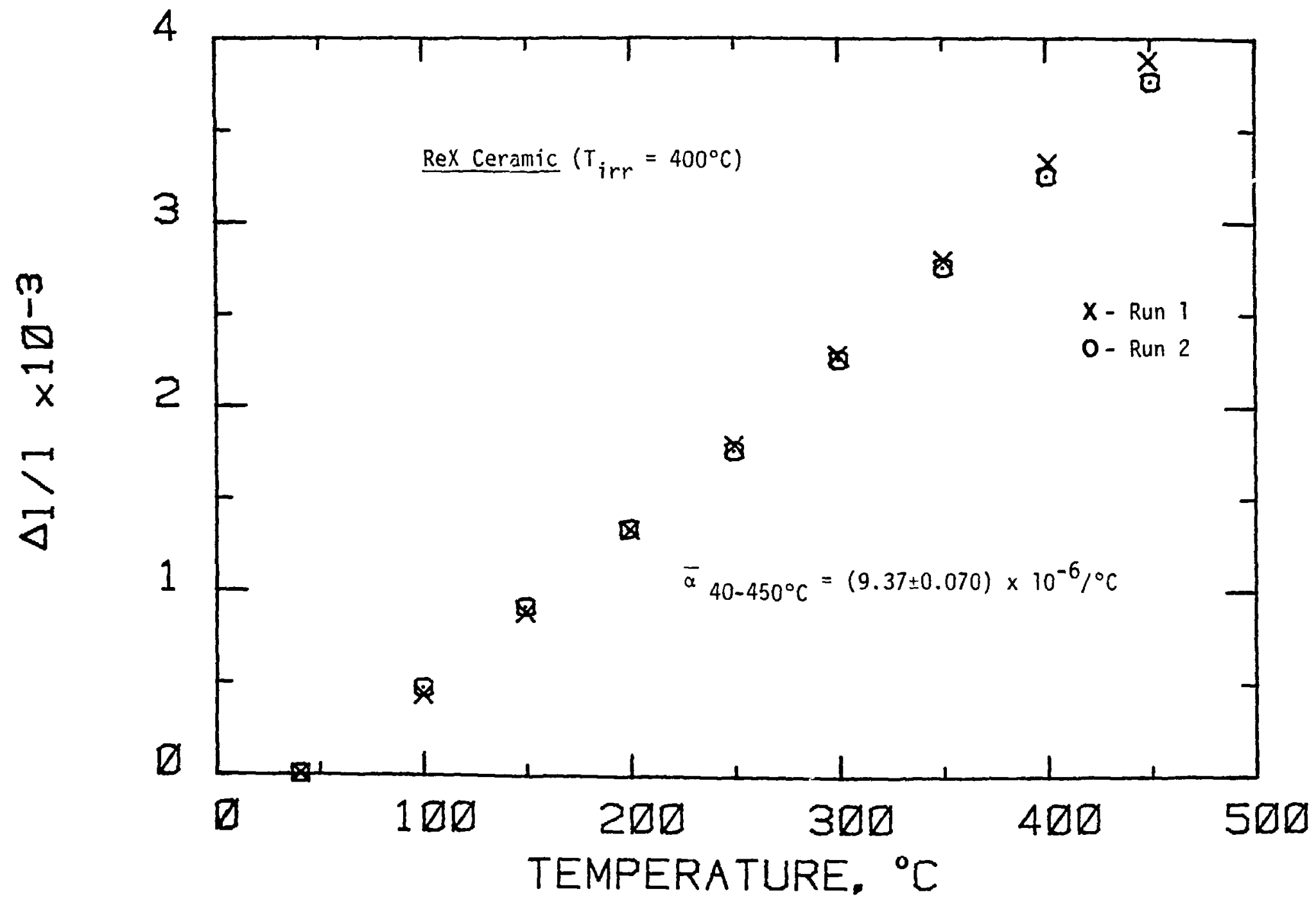

Fig. 25 Thermal Expansion Data for $400^{\circ} \mathrm{C}$ Neutron-irradiated ReX Glass Ceramic (ceramic form) 


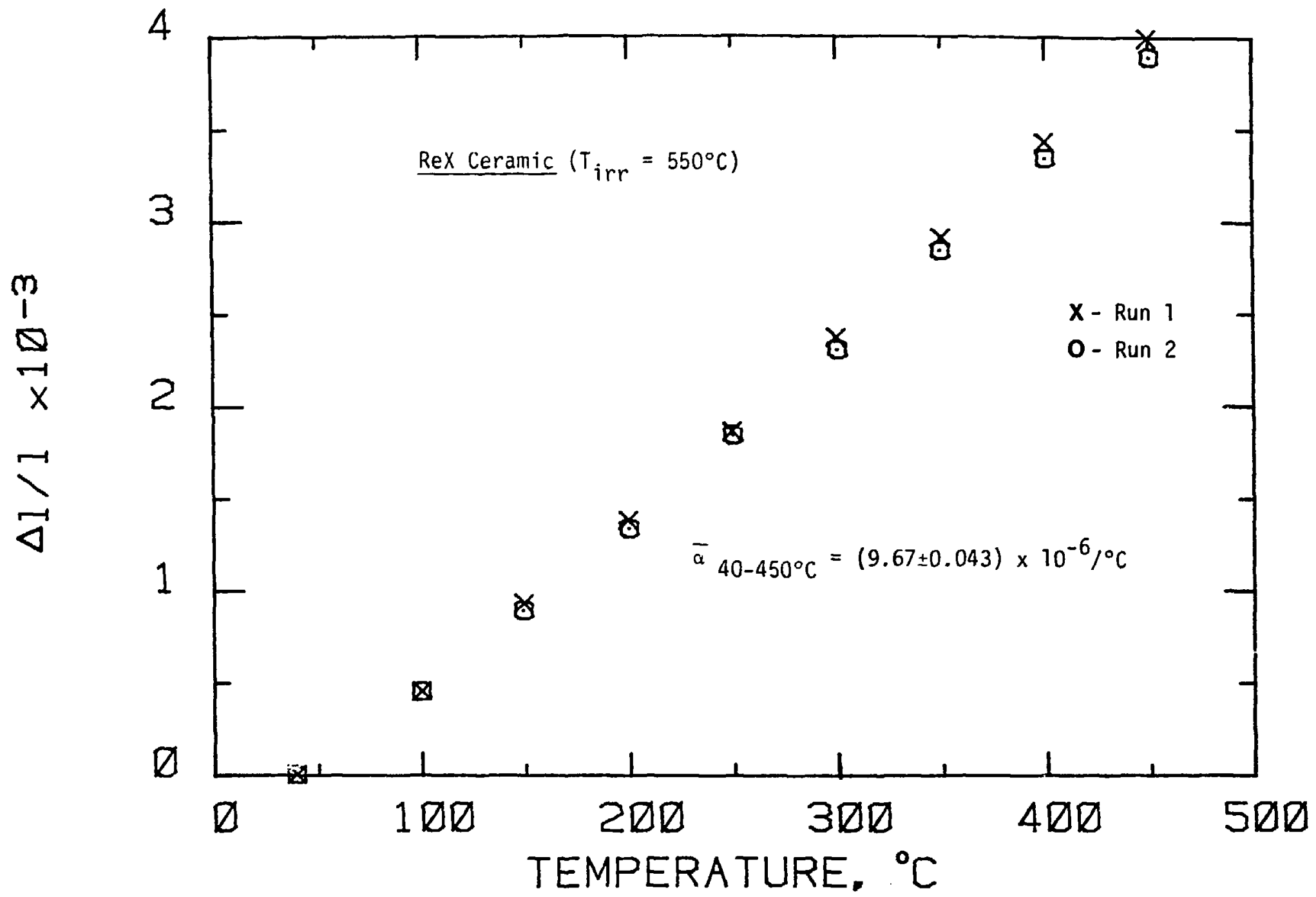

Fig. 26 Thermal Expansion Data for $550^{\circ} \mathrm{C}$ Neutron-irradiated ReX Glass Ceramic (ceramic form) 


\section{Corning Glass Ceramics: Macor, DH, DI, and DJ}

The Corning-supplied giass ceramics, whose crystalline phases are fluorophogapite micas were sealed in vacuum so that subsequent gas-release analysis could be made, were only recently de-encapsulated. Laser puncturing of the capusles indicated no gas release from the $D H, D I$, and $D J$ materials during irradiation. This conclusion assumes that if $\mathrm{O}_{2}$ and $\mathrm{F}$ had been released, it did not all react with the stainless steel capsule material; Auger surface analysis of the inner capsule wall will be used to confirm this. The Macor did release He, and therefore probabiy some tritium $\left({ }^{3} \mathrm{~T}\right)$ gas. The capsule containing $\sim 0.21 \mathrm{~g}$ of Macor, irradiated at $550^{\circ} \mathrm{C}$ to a fast neutron fluence of $2.73 \times 10^{22} \mathrm{n} / \mathrm{cm}^{2}$, was found to contain $16.5 \mathrm{psig}\left(25^{\circ} \mathrm{C}\right)$ of He. This represents $6.93 \times 10^{18}$ atoms of He. Assuming that the He was created by neutron reactions with the ${ }^{10} \mathrm{~B}$ contained in the Macor, these reactions are:

$$
\begin{aligned}
& { }^{10} \mathrm{~B}\left(\mathrm{~N},{ }^{3} \mathrm{~T}+2 \mathrm{He}\right) \text {, and } \\
& { }^{10} \mathrm{~B}(\mathrm{~N}, \mathrm{He}) \mathrm{Li}^{7}
\end{aligned}
$$

Using previous results for the Row 7 neutron spectrum interaction with $\mathrm{B}_{4} \mathrm{C}$ materials, we can predict that $\sim 3.8 \times 10^{19}$ atoms of He were created, indicating that only $20 \%$ were released to the capsule plenum.

Density results (Table 10 ) indicate that the Macor did swell 1\%, this perhaps due to the He generation. The density results on the $\mathrm{DH}$, $D I$, and DJ materials indicated slightly greater swelling(2-3\%). 
Transmission electron microscopic examinations revealed that no significant loss of crystallinity had occurred. Comparisons to unirradiated materials, however, did reveal that some of the irradiated materials (DH) developed lens-shaped defects (see Fig. 27) on the faces of the mica plates. These could have resulted in the slight density reduction. DH samples often fell apart during simple handling. The obvious strength reduction was likely due to these lens-shaped defects, the bonds between mica plates being weakened. The Macor itself did not seem to form these defects although it was susceptible to a radiation annealing phenomenon similar, but less pronounced, to that observed in ReX. The DH material showed no such annealing effects.

Table 10 -- Corning Glass Ceramics Density Results

\begin{tabular}{|c|c|c|c|}
\hline Material & $\Delta V / V_{0}, \%$ & $\mathrm{~T}_{\text {irr }},{ }^{\circ} \mathrm{C}$ & $\phi \mathrm{t}, 10^{22} \mathrm{n} / \mathrm{cm}^{2}$ \\
\hline Macor & 1.1 & 550 & 2.73 \\
\hline $\mathrm{DH}$ & 1.5 & 400 & 2.31 \\
\hline $\mathrm{DH}$ & 0.7 & 550 & 2.68 \\
\hline $\mathrm{DI}$ & 3.0 & 400 & 1.94 \\
\hline DI & 2,1 & 550 & 2.24 \\
\hline DJ & 2.8 & 400 & 2.17 \\
\hline DJ & 2.0 & 550 & 2.51 \\
\hline
\end{tabular}



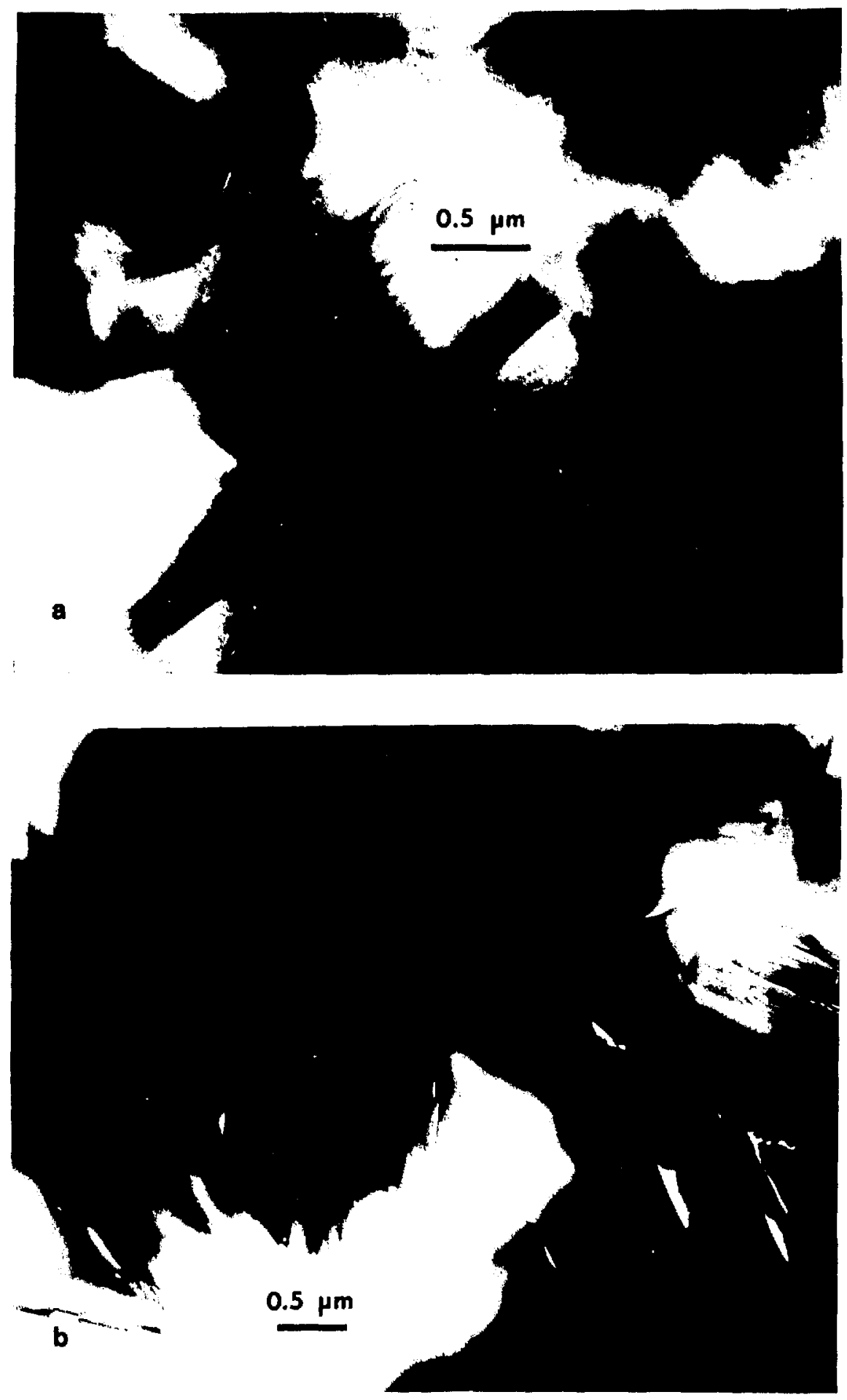

Figure 27. Transmission Electron Micrographs of Unirradiated (a) and Neutron-irradiated (b) DH Glass Ceramic. Note the irradiation-induced lens-shaped defects which formed between mica plates causing weakening of the material. $200 \mathrm{kV}$. 
$\mathrm{ZrO}_{2}$

The partially-stabilized zirconias have not yet been examined.

\section{CONCLUSIONS}

Many results have already been accumulated in the program although a great deal more are still planned. Property changes in some of the ceramics have been found to be less than expected ( $R e X)$ from an engineering use viewpoint; the properties of other ceramic materials ( $\mathrm{OH}-s t r e n g t h$, Infracilcoloration, etc.) were altered significantly, which could preclude their use in fusion reactor applications. In addition, several examples of discrepancies between neutron-irradiation results and electron simulation have been identified, showing the need for neutron data. I believe the initial results have proven the importance of obtaining data of this type.

\section{ACKNOWLEDGEMENTS}

The author wishes to thank R. Eagen and S. Lappin (Sandia); A. Tobin (Grumman Aircraft); F. Clinard and G. Hurley (LANL); R. Youngman, M. Pascucci, and T. Mitchell (CWRU); B. Olbert (Penn State U.); C. Wilkes, E. Wood, and R. Martell (ANL) for helping get this experiment started and built, for supplying materials to be irradiated, and for helping with many of the post-irradiation examinations performed in this study. 


\section{REFERENCES}

1. L. W. Hobbs, J. Am. Ceram. Soc., 62 (1979) 267.

2. J. M. Bunch, J. G. Hoffman, and A. H. Zeltmann, J. Nucl. Mater., 73 (1978) 65.

3. M. D. Rechtin, Rad. Effects, 42 (1979) 129.

4. F. W. Clinard, Jr., J. Nucl. Mater., 85-86 (1979) 393.

5. W. Primak, J. Nuc 1. Mater., 85-86 (1979) 405.

6. A. Pehavi and N. Kristianpoller, Phys. Stat. Solidi (a), $\underline{57}$ (1980) 221.

7. R. A. Youngman, F. W. Clinard, L. W. Hobbs, and T. E. Mitchell, Proc. of the 37th Annual EMSA Meeting, p. 418.

8. G. B. Krefft, Rad. Effects, 49 (1980) 127.

9. G. F. Hurley and J. M. Bunch, LANL Controlled Thermonuclear Research Program Progess Report for 1977, LA-7474-PR.

10. G. W. Keilholtz, J. E. Lee, Jr., and R. E. Moore, in Nuclear Application of Nonfissionable Ceramics, A. Boltax and J. H. Handwerk Eds. (Am. Nuc7. Soc., Hinsdale, Illinois, 1966) 133.

11. N. A. Ibrahim and K. Tangri, Phil. Mag., 34 (1976) 701.

12. M. R. Pascucci and L. W. Hobbs, J. Am. Ceram. Slc., in press.

13. A. J. Leadbetter, P. A. Phillips, and A. F. Wright, Phil. Mag., 34 (1976) 453.

14. W. Primak, Nuci. Sci. and Eng., 65- (1978) 141.

15. U. Katenkamp, H. Karge, and R. Prager, Rad. Effects, 48 (1980) 31. 
DISTRIBUTION FOR ANL/FPP/TM-166

Internal
M. Abdou
D. Gruen
D. Porter (20)
C. Baker
A. Hassanein
W. Praeg
C. Boley
C. Johnson
D. Smith
J. Brooks
J. Jung
M. Kaminsky
R. Smith
F. Cafasso
S. Kim
D. Cissel
Y-K. Kim
R. Clemmer
R. Kustom
D. Ehst
B. Loomis
K. Evans
V. Maroni
$Y$. Goha
R. Mattas
L. Greenwood
R. Nygren
M. Steindler
R. Teunis
L. Turner
FPP Files (10)
ANL Contract File
ANL Libraries (2)
ANL Patent Dept.
TIS Files (6)

\section{External}

DOE-TIC, for distribution per UC-20 (108)

Manager, Chicago Operations Office, DOE

University of Chicago Special Committee for the Fusion Program:

S. Baron, Burns \& Roe, Inc.

H. Forsen, Bechtel National, Inc.

M. Lubin, Standard $0 i 1$ Company of Ohio

G. Miley, University of Illinois

P. Reardon, Princeton Plasma Physics Laboratory

D. Steiner, Rensselaer Polytechnic Institute

K. Symon, University of Wiscons in

K. Thomassen, Lawrence Livermore National Laboratory 